\title{
บUisuersily
}

\section{Long-Term Implications of Antibiotic Use on Gut Health and Microbiota in Populations Including Patients With Cystic Fibrosis}

Deane, J., Rea, M. C., Fouhy, F., Stanton, C., Ross, R. P., \& Plant, B. J. (Accepted/ln press). Long-Term Implications of Antibiotic Use on Gut Health and Microbiota in Populations Including Patients With Cystic Fibrosis. In The brain-gut axis- Dietary, Probiotic, and Prebiotic Interventions on the Microbiota (Vol. 1, pp. 223259). Elsevier. https://doi.org/10.1016/B978-0-12-802304-4.00011-6

Link to publication record in Ulster University Research Portal

\section{Published in:}

The brain-gut axis- Dietary, Probiotic, and Prebiotic Interventions on the Microbiota

\section{Publication Status:}

Accepted/In press: 01/05/2016

DOI:

10.1016/B978-0-12-802304-4.00011-6

\section{Document Version}

Publisher's PDF, also known as Version of record

\section{General rights}

Copyright for the publications made accessible via Ulster University's Research Portal is retained by the author(s) and / or other copyright owners and it is a condition of accessing these publications that users recognise and abide by the legal requirements associated with these rights.

\section{Take down policy}

The Research Portal is Ulster University's institutional repository that provides access to Ulster's research outputs. Every effort has been made to ensure that content in the Research Portal does not infringe any person's rights, or applicable UK laws. If you discover content in the Research Portal that you believe breaches copyright or violates any law, please contact pure-support@ulster.ac.uk. 


\section{CHAPTER}

\section{Long-Term Implications of Antibiotic Use on Gut Health and Microbiota in

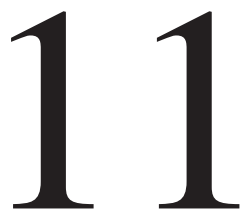 Populations Including Patients With Cystic Fibrosis}

J. Deane

Teagasc Food Research Centre, Cork, Ireland; University College Cork, Department of Medicine,

Cork, Ireland

M.C. Rea

Teagasc Food Research Centre, Fermoy, Cork, Ireland; University College Cork, APC Microbiome Institute, Cork, Ireland

F. Fouhy

Teagasc Food Research Centre, Fermoy, Cork, Ireland

C. Stanton

Teagasc Food Research Centre, Fermoy, Cork, Ireland; University College Cork, APC Microbiome Institute, Cork, Ireland

R.P. Ross

University College Cork, APC Microbiome Institute, Cork, Ireland; University College Cork, College of Science, Engineering and Food Science, Cork, Ireland

B.J. Plant

University College Cork, Cork Cystic Fibrosis Centre, Cork University Hospital, Cork, Ireland; University College Cork, Department of Medicine, Cork, Ireland

\section{INTRODUCTION}

Since the discovery by Alexander Fleming of penicillin in 1929 and the subsequent journey of antibiotic research and discovery, antibiotics have revolutionized human health on a global scale. Antibiotic therapy can be acknowledged for a significant increase in life expectancy between 1944 and 1972, a period of intensive and successful antibiotic research (Cotter et al., 2012). However, the negative effects of antibiotic therapy are well documented, most notably antimicrobial resistance, which is now accepted as a global issue spanning medical, economic, and environmental fronts. The World Health Organization, Centers for Disease Control and Prevention (CDC), 
and European Center for Disease Prevention and Control consider multidrug-resistant (MDR) infections caused by antibiotic-resistant bacteria as an emergent global disease and a major threat to public health (Roca et al., 2015). However, this review will focus on the more pervasive effects of antibiotic therapy on the gut microbiome and the far-reaching effects on the health of the host. The antibiotic-mediated perturbations of the microbiome and disruption of related functionality is an area of much research. In recent years the collateral damage caused by antibiotic use has come into focus (Blaser, 2011). Antibiotic therapy can be likened to a war of attrition on the gut microbiota because subsequent rounds of therapy result in loss of diversity followed by incomplete recovery causing the bacterial population to shift from the initial assemblage. The control of infection through antibiotic use, while not diminishing its importance, has potentially devastating consequences downstream not only for the individual, as host-microbe interactions are disturbed, but also for society with the potential dissemination of MDR determinants. In this review we examine the literature regarding the effects of various families of antibiotics on the gut microbiota, discussing in particular issues with relevance to a cystic fibrosis $(\mathrm{CF})$ cohort, such as MDR as a result of chronic antibiotic use, Clostridium difficile, and disruption of host-microbiota mutualistic relationships.

Perturbations of the gut microbiota can occur via many external environmental factors, but perhaps the most dramatic modulatory effects are seen with antibiotic use. The immediate impact of short-term antibiotic therapy on the gut microbiota is extensively investigated. However, longitudinal studies mapping the recovery of the microbiota in the aftermath are limited, with even greater gaps in our knowledge regarding the long-term effects of chronic antibiotic use on the gut microbiota. Studies focusing on short-term antibiotic use have demonstrated the profound and pervasive effects of the antibiotic, the resilience of the gut microbiota after treatment (Dethlefsen et al., 2008; Jernberg et al., 2007), and reduction of fecal bacterial load and diversity (Xu et al., 2014; Iapichino et al., 2008; Jakobsson et al., 2010). Others have demonstrated the differential effects of different classes of antibiotics on the gut microbiota and how the resultant assembly after antibiotic treatment may be influenced by mode of action (Perez-Cobas et al., 2013). It is widely reported that immediately after antibiotic treatment an increase in Enterococcus species (Iapichino et al., 2008) and a decrease in Bifidobacteria, Clostridia, Desulfovibrio, Faecalibacterium and Bacteroides species (Adamsson et al., 1999; Bartosch et al., 2004; Jernberg et al., 2007; O’Sullivan et al., 2013) is expected. Most microbiota recover after 4 weeks; however, a long-term persistence of expressed antibiotic resistance genes, particularly carried by Enterococcus species, after a short-term antibiotic treatment was noted up to 4 years posttreatment in some human studies (Jakobsson et al., 2010; Jernberg et al., 2007).

CF cohorts are ideal candidate groups to investigate the effects of antibiotic use on gut health and microbiota. CF is a monogenic disorder, thereby reducing confounding factors and so facilitating inferences regarding antibiotic effects on the gut microbiota. $\mathrm{CF}$ is a potentially life-threatening autosomal-recessive disorder affecting 70,000 individuals worldwide, with Ireland having the highest prevalence $(\sim 1100$ patients) and incidence rates (1 in 1353; Farrell, 2008). It results from mutations in 
the cystic fibrosis transmembrane conductance regulator (CFTR) gene, located on the long arm of chromosome 7 (Collins, 1992), of which the most common is $\Delta F 508$ (a deletion of phenylalanine at codon 508). CFTR gene mutations result in defective chloride ion transport in the respiratory, hepatobiliary, gastrointestinal, reproductive tracts, and the pancreas (Quinton, 1990). The natural progression of CF is characterized by chronic lung function decline punctuated by recurrent periods of temporary worsening of symptoms, known as pulmonary exacerbations (Amadori et al., 2009; Flume et al., 2009). Prophylactic antibiotic therapy plays a pivotal role in treating $\mathrm{CF}$ patients; combating frequent lung infections, slowing the rate of lung function decline, and ultimately prolonging life. Indeed antibiotic discovery, amongst other therapeutic options, has significantly contributed to the increased life expectancy of CF sufferers, meaning many survive into their thirties and beyond whereas in the 1950s few lived to attend primary school. The increasing life expectancy of CF individuals presents further new therapeutic challenges (Plant et al., 2013). A global shifting pattern of antibiotic use is seen in antibiotic therapy for CF patients in which prophylaxis, maintenance, and chronic antibiotic therapy have been shown to improve clinical outcomes and survival (Moskowitz et al., 2008; Szaff et al., 1983).

Although the gut microbiota of CF patients is poorly documented, it can be assumed that intensive and frequent courses of antibiotics alter its diversity and function as a symbiotic partner with the host. Seventy percent of the immune system is harbored in the gastrointestinal tract, meaning perturbations in the microbiome at the very least will have implications for host immunity, but also for energy extraction efficiency from food, mental well-being, and colonization resistance against pathogenic microorganisms (Weiner, 2000; Faria and Weiner, 2005; Vighi et al., 2008). Defining and characterizing the gut microbiota of a $\mathrm{CF}$ population can provide information applicable to the wider medical community. A picture of the gut microbiota of $\mathrm{CF}$ patients as a unique entity that is a signature of the disease is emerging in recent research. The characteristic $\mathrm{CF}$ intestinal microbiome is thought to be as a result of a combination of factors including the CFTR malfunction itself, chronic antibiotic use, high-fat diet, pancreatic enzyme supplementation, and suppression of gastric acid (Bruzzese et al., 2014). The $\mathrm{CF}$ gut has been shown to have lower counts of lactic acid bacteria (LAB), Clostridium species, Bifidobacterium species, Veillonella species, and Bacteroides-Prevotella species, whereas Enterobacteriaceae counts were increased in the CF cohort (Duytchaever et al., 2011). As expected in a cohort with chronic antibiotic use, CF patients have been shown to have lower species richness, evenness, diversity, and reduced temporal stability of intestinal microbiota (Scanlan et al., 2012). In particular, the reduction of diversity and abundance of Bifidobacterium species (Bifidobacterium longum, Bifidobacterium catenulatum, Bifidobacterium pseudocatenulatum, and Bifidobacterium adolescentis), Clostridium cluster XIVa, and Clostridium cluster IV (R. bromii and Faecalibacterium prausnitzii) has been described (Duytschaever et al., 2013). Bifidobacterium species have a greater antimicrobial susceptibility to many antibiotics used in the treatment of CF pulmonary exacerbations and reduced adhesion capacity to inflamed mucosa (Lee and O'Sullivan, 2010; Russell et al., 2011), perhaps explaining their reduction in a CF cohort. Evidence from Madan et al. (2012) revealed a core lung-gut microbiota 
dominated by Veillonella and Streptococcus, with similarities between population fluctuations between the two sites. Furthermore, they show that select genera (Roseburia, Dorea, Sporacetigenium, Coprococcus, Blautia, Enterococcus, and Escherichia) of the gut microbiota precede bacterial populations found in the lung. Allelic variations of the CFTR gene have also been shown to have effects on the gut microbiota, with homozygous F508del and severe disease phenotype CF patients exhibiting greater dysbiotic fecal microbiota compared with heterozygous milder disease phenotype patients, a signature most likely reflective of reduced therapies (Schippa et al., 2013). It is hypothesized that imbalance of the intestinal microbiota of CF patients may be associated with causes, or aids, the progression of the disease and may be a predictor of expected outcomes after antibiotic therapy (Duytschaever et al., 2011).

\section{ANTIBIOTICS USE AMONG PERSONS WITH CYSTIC FIBROSIS}

Antibiotic regimens for $\mathrm{CF}$ patients currently follow one of the following strategies: a symptomatic regimen that is treatment of pulmonary exacerbation upon notice of acute symptoms (Elphick and Tan, 2005) or elective regimens that may comprise treatment of the chronic infection with intravenous, inhaled, and/or oral antibiotics at regular intervals to delay or prevent long-term deterioration in the absence of recent clinical deterioration (Høiby, 1993; Moskowitz et al., 2008). The latter elective regimens constitute chronic antibiotic usage or prophylaxis and have become routine practice to prevent or delay pulmonary exacerbations. CF patients typically undergo antibiotic treatment involving a combination of inhaled and oral therapies as well as potentially intravenous treatments from different mechanistic classes (eg, ceftazidime and tobramycin; Smyth et al., 2014; Flume et al., 2009). With the advent of efficient nebulization devices in the 1990s, inhaled antibiotics became the mainstay in CF therapy maintenance, enabling eradication of initial Pseudomonas infection (Ramsey et al., 1999; Pamukcu et al., 1995; Wall et al., 1983; Moskowitz et al., 2008; Gibson et al., 2003). Inhaled antibiotics result in greater concentrations arriving directly to the respiratory system secretions, local to the infection (Moskowitz et al., 2008). Nebulized/inhaled tobramycin, aztreonam, and colistin form the main therapeutic options for eradication and/or suppression of Pseudomonas aeruginosa in the lung (Döring et al., 2012). Nebulization duration is associated with a significant treatment burden on the patient and may result in poorer clinical outcomes because of reduced compliance with the treatment regimen (Sawicki and Tiddens, 2012). Advances in addressing patient treatment burden are seen with the emergence of portable dry powder formulations of tobramycin (TOBI podhaler) and colistimethate sodium (Colobreathe; Konstan et al., 2011; Schuster et al., 2013; Uttley et al., 2013). Rapid delivery systems for antibiotic therapies via portable inhalers significantly reduce treatment burden and increase adherence (Harrison et al., 2014).

The success of a particular antibiotic treatment regimen is assessed primarily by considering its efficacy at suppression or eradication of the infectious agents and subsequent improvement in lung function, measured as $\mathrm{FEV}_{1}$ (Forced Expiratory 
Volume in the first second). In addition to the need for hospitalization, the length of time until the requirement for additional antibiotics, the time to reoccurrence of pulmonary exacerbation, the number and severity of adverse events experienced by patients, and the convenience and patient satisfaction (hence ease of compliance) for the patient are factors considered.

\section{THE MODULATORY EFFECTS OF SPECIFIC ANTIBIOTICS ON THE GUT MICROBIOTA (NON-CYSTIC FIBROSIS HOSTS)}

The human gut microbiota is individual specific at the bacterial strain level (Turnbaugh and Gordon, 2009; Lozupone et al., 2012; Schloissnig et al., 2013). How antibiotic therapies interact and perturb the microbiota varies between individuals, with individuals on the same antibiotic, dose, and time showing varying effects, albeit similar trends (Perez-Cobas et al., 2013). Dethlefsen et al. (2008) showed not only interindividual variation in response to ciprofloxacin but also different responses of taxa. Grouping of metagenomic data from several individuals may mask individual perturbations. Therefore it is preferable to measure distance from baseline in each individual to reveal the true effect of the antibiotic treatment (Engelbrektson et al., 2006). Diet, genetics, and health status as well as the dynamics of the microbiota itself may contribute to stability within the intestinal microbiota, enabling some communities to have more resilience than others in response to antibiotic therapy (Perez-Cobas et al., 2013). This elaborate network fed by numerous variables presents a huge challenge when analyzing microbiota responses to antibiotic treatment. Countering the effect of the antibiotic is the resilience and stability of the microbiota. The balance of the microbiota to external pressures is mediated by host-microbe interactions, microbe-microbe interactions, and physiochemical factors (Edlund et al., 2000).

The effects of antibiotics on the gut microbiome are unique to each antibiotic and depend on several factors: the target spectra, the dose and duration, the method of administration and the pharmacokinetic and pharmacodynamic properties of the agent (incomplete absorption or secretion of intravenous antibiotics by bile or intestinal mucosa may result in higher concentrations in the intestine with greater ecological effects; Edlund et al., 2000; Jernberg et al., 2010; Adamsson et al., 1999). Disturbances may be assessed (1) qualitatively (emergence of novel bacteria types with resistance genes, plasmids, and transposons) or (2) quantitatively (changes in microbiota composition due to antibiotic pressures; Edlund et al., 2000). Broadspectrum antibiotic treatments affect not only the aberrant pathogenic bacteria but also beneficial members of the gut community, reduce diversity and richness, and disturb the ecology of the gut (Jernberg et al., 2007; Dethlefsen and Relman, 2011; O' Sullivan et al., 2012). However, it remains a challenge to distinguish antibiotic effects on the gut microbiota from other confounding factors such as stress, diet and host genetics (Jernberg et al., 2010). The route of administration has implications for antibiotic-mediated disturbances in the gut microbiota because oral, inhaled and intravenous routes result in different concentrations in different sites (Liu and Derendorf, 2003; Liu et al., 2002). 
The gut microbiota has a degree of resilience to antibiotic treatment, the strength of which may vary depending on which microorganisms form a given individual's microbiota, some conferring more stability than others. Recovery of gut microbiota is often rapid, ranging from 2 days (Dethlefsen and Relman, 2011) to 2 weeks (Ubeda et al., 2010); however, individual taxa have different recovery rates, some slower than others as seen with increased proportions of Lachnospiracaea and Clostridiacaea by Antonopoulos and colleagues (2009) 6 weeks posttreatment with cefoperazone. For many, recovery is often incomplete or partial (Dethlefsen and Relman, 2011). This resilience may be apparent in the first round of therapy, and it is in subsequent, repetitive or prolonged rounds of therapy that shifts in the microbiota may be seen (Perez-Cobas et al., 2013). The magnitude and rate of the response is primarily dictated by the initial microbial community, with some communities displaying a prolonged directional shift and others a more rapid response (Dethlefsen and Relman, 2011). Initial community composition could be an important indication of expected outcomes after antibiotic use, such as likelihood of pathogen overgrowth or development of antibiotic-associated diarrhea (AAD; De La Cochetiere et al., 2008; Ozaki et al., 2004). Although the gut microbiota is stable, it is never static. Its periodic variations within a normal range make it difficult to definitively attribute loss or gain of certain taxa to certain antibiotics. Dethlefsen and Relman (2011) explain that the long-term stability of the gut microbiota is maintained by restoring forces after external disturbances rather than rigidity or resistance to change. However, the restoring forces will not withstand repeated antibiotic courses, even in cases in which the microbiota has completely recovered after an initial antibiotic treatment.

Antibiotics families vary in mode of action and target specificity and therefore in the fingerprint they leave on the gut microbiota. Perez-Cobas et al. (2013) showed that the greatest influence on the microbiota is the antimicrobial effect and the mode of antibiotic action. At the compositional level, the mode of action exerts the greatest effect, although at the functional level the antimicrobial effect is the driving force (Perez-Cobas et al., 2013). The mode of action of the antimicrobial agent produces different effects on the gut community. O'Sullivan et al. (2013) noted a significantly greater reduction of Bifidobacterium species and significant differences in levels of Anaerococcus, Denitrobacterium, Faecalibacterium, Lactonifactor, and Proteus species in subjects receiving only a nucleic acid inhibitor compared with subjects on antibiotics with cell envelope mode of action, whereas subjects receiving only cell envelope antibiotics had significantly increased levels (10-fold) of Lactobacillus species and significant differences in levels of Ascomycota and Elusimicrobia. They concluded that cell envelope inhibitors had less impact on the intestinal microbiota than nucleic acid synthesis inhibitors. The effects are taxa specific with some more susceptible than others; however, signatures of antimicrobial classes can be seen in bacterial profiles after treatment, with individuals' diverse microbiota converging to similar compositions when administered the same antibiotic (Perez-Cobas et al., 2013; Jernberg et al., 2010; Antonopoulos et al., 2009). The selection of antibiotic should be based not only on the expected success of the antibiotic treatment but also on the level of ecological disturbances (Edlund et al., 2000). There is a lack of information 
detailing the effects of chronic usage of different antibiotic classes on the gut microbiota. Here we discuss the signatures produced by short-term use of different antibiotic classes, as shown in human studies, unless stated otherwise. See Table 11.1 for a summary of the effects of specific antibiotic classes on the intestinal microbiota.

\section{Macrolides}

Macrolides are so called because of their macrocyclic ring, which may be 14, 15, or 16 membered (Hamilton-Miller, 1992). They have a protein synthesis inhibitory mode of action. Macrolides have been shown to inhibit protein synthesis by causing a dissociation of the peptidyl-tRNA from the ribosome (Tenson et al., 2003). Azithromycin has been shown to significantly improve quality of life in CF patients, reduce $\mathrm{C}$-reactive protein levels, reduce the rate of lung function decline $\left(\mathrm{FEV}_{1}\right.$ measurements), reduce the number of respiratory exacerbations, and significantly reduce systemic inflammation (Saiman et al., 2003; Wolter et al., 2002). Azithromycin is chosen for macrolide therapy over other macrolides, such as erythromycin, because of less adverse effects on the gastrointestinal tract. Azithromycin is also known to have negative effects on the bacterial motility of $P$. aeruginosa through suppression of flagellin expression at subinhibitory concentrations (Kawamura-Sato et al., 2000). In a study of three adults presenting with gastric and duodenal ulcers, Jakobsson et al. (2010) showed the negative impact of Clarithromycin on members of the Actinobacteria phyla; significant reductions of Escherichia coli; suppression of Bifidobacterium, Lactobacillus, and Clostridium species; and an increase in Enterococcus, Enterobacter, Citrobacter, Klebsiella, and Pseudomonas species. Clarithromycin has been shown to strongly suppress anaerobic populations in a study of healthy adults comparing Clarithromycin to a fluoroquinolone, moxifloxacin-based treatment regimen (Adamsson et al., 1999; Brismar et al., 1991; Edlund et al., 2000). This has important implications for total ecological disturbances because the anaerobic population is mainly responsible for colonization resistance (Waaij, 1989; Hertz et al., 2014). Adamsson et al. (1999) also showed a significant qualitative change with an increase of resistant Bacteroides from $2 \%$ to $76 \%$ in a study of 30 adults with Helicobacter pylori infection. This indicates an antibiotic class with the ability for ecological disruption and promotion of resistant strains. This contrasts with the findings of Morotomi et al. (2011), which show that macrolide antibiotic treatments tended toward dominance of Streptococcus species and seemed to have less dramatic effects on the microbiota with samples remaining similar to healthy intestinal microbiota in a study of 29 healthy adults (Morotomi et al., 2011).

\section{$\beta$-Lactams}

$\beta$-Lactams, encompassing cephalosporins, carbapenems, penicillins, monobactams, and cephamycins, are considered the most successful antibiotic class discovered (Lewis, 2013). $\beta$-Lactams form an important part of treatment of pulmonary exacerbation for CF patients. Ceftazidime, meropenem, flucloxacillin, piperacillin/taxobactam, and aztreonam are all $\beta$-lactam therapies commonly used by $\mathrm{CF}$ patients. $\beta$-Lactams have a bactericidal mode of action that disrupts cell wall synthesis, 
Table 11.1 Summary of the Effects of Specific Antibiotic Classes on the Intestinal Microbiota

\begin{tabular}{|c|c|c|c|c|}
\hline Antibiotic Class & $\begin{array}{l}\text { Specific } \\
\text { Antibiotic } \\
\text { Examples }\end{array}$ & Mode of Action & Gut Microbiota Effects & References \\
\hline Macrolides & $\begin{array}{l}\text { Azithromycin, } \\
\text { erythromycin, } \\
\text { clarithromycin }\end{array}$ & $\begin{array}{l}\text { Protein synthesis inhibitory mode of } \\
\text { action by initiating a dissociation } \\
\text { of the peptidyl-tRNA from the } \\
\text { ribosome. }\end{array}$ & $\begin{array}{l}\text { Clarithromycin has been shown to reduce } \\
\text { Actinobacteria phyla, E. coli, bifidobacte- } \\
\text { ria, lactobacilli, clostridia, and anaerobic } \\
\text { populations and increase enterococci, } \\
\text { Enterobacter, Citrobacter, Klebsiella, } \\
\text { Pseudomonas, and resistant Bacteroides. }\end{array}$ & $\begin{array}{l}\text { Jakobsson et al. } \\
\text { (2010) } \\
\text { Adamsson et al. } \\
\text { (1999) } \\
\text { Brismar et al. (1991) } \\
\text { Edlund et al. (2000) }\end{array}$ \\
\hline$\beta$-Lactams & $\begin{array}{l}\text { Penicillin, } \\
\text { ceftazidime, } \\
\text { meropenem, } \\
\text { flucloxacillin, } \\
\text { coamoxiclav, } \\
\text { piperacillin/ } \\
\text { tazobactam, } \\
\text { aztreonam }\end{array}$ & $\begin{array}{l}\text { Bactericidal mode of action, } \\
\text { disrupting cell wall synthesis, } \\
\text { specifically in the final cross-linking } \\
\text { stage of the peptidoglycan layer. }\end{array}$ & $\begin{array}{l}\text { Increase of Bacteroides, Blautia, } \\
\text { Faecalibacterium, Parabacteroides- } \\
\text { most probably due to high rate of } \\
\text { resistance in these genera. Significant } \\
\text { reduction of anaerobic population. }\end{array}$ & $\begin{array}{l}\text { Perez-Cobas et al. } \\
\text { (2013) } \\
\text { Monreal et al. (2005) } \\
\text { Morotomi et al. } \\
\text { (2011) } \\
\text { Adamsson et al. } \\
\text { (1999) }\end{array}$ \\
\hline Lincosamides & Clindamycin & $\begin{array}{l}\text { Bacteriostatic antimicrobial effect } \\
\text { and protein synthesis mode of } \\
\text { action. }\end{array}$ & $\begin{array}{l}\text { Decreases in Bacteroides and Blautia. } \\
\text { Increase in Enterobacteriaceae. }\end{array}$ & $\begin{array}{l}\text { Perez-Cobas et al. } \\
\text { (2013) }\end{array}$ \\
\hline Fluoroquinolones & $\begin{array}{l}\text { Moxifloxacin, } \\
\text { ciprofloxacin }\end{array}$ & $\begin{array}{l}\text { Inhibition of DNA gyrase and } \\
\text { topoisomerase IV. Fluoroquinolones } \\
\text { sequester these enzymes into a } \\
\text { drug/enzyme/DNA complex that } \\
\text { holds double-stranded DNA breaks } \\
\text { together, blocking replication. }\end{array}$ & $\begin{array}{l}\text { Decrease in Faecalibacterium, } \\
\text { Bacteroides, enterococci, enterobacteria. } \\
\text { Clostridia, Bifidobacteria, } \\
\text { Lachnospiraceae, Ruminococcaceae, and } \\
\text { Enterobacteriaceae. }\end{array}$ & $\begin{array}{l}\text { Perez-Cobas et al. } \\
\text { (2013) } \\
\text { Dethlefsen and } \\
\text { Relman (2011) } \\
\text { Edlund et al. (2000) }\end{array}$ \\
\hline
\end{tabular}


Table 11.1 Summary of the Effects of Specific Antibiotic Classes on the Intestinal Microbiota—cont'd

\begin{tabular}{|c|c|c|c|c|}
\hline Antibiotic Class & $\begin{array}{l}\text { Specific } \\
\text { Antibiotic } \\
\text { Examples }\end{array}$ & Mode of Action & Gut Microbiota Effects & References \\
\hline Polymyxins & $\begin{array}{l}\text { Colistin } \\
\text { sulfomethate }\end{array}$ & $\begin{array}{l}\text { Induces changes to the permeability } \\
\text { of the cell wall by binding anionic } \\
\text { lipopolysaccharide molecules and } \\
\text { displacing calcium and magnesium, } \\
\text { leading to cell leakage and death. }\end{array}$ & $\begin{array}{l}\text { Orally administered colistin is poorly } \\
\text { absorbed in the gut; therefore it has little } \\
\text { effect on the intestinal microbiota. }\end{array}$ & WHO (2006) \\
\hline Nitroimidazoles & Metronidazole & $\begin{array}{l}\text { Entering cell in inactive state, } \\
\text { becoming activated in the bacterial } \\
\text { cytoplasm through electron transfer } \\
\text { of the nitro group of the drug to a } \\
\text { cytotoxic state with DNA-binding } \\
\text { capabilities. }\end{array}$ & $\begin{array}{l}\text { Active against anaerobic bacteria. } \\
\text { Decreases in Firmicutes and Bacteroidetes } \\
\text { and increases in Enterobacteriaceae. } \\
\text { Metronidazole concentration appears low } \\
\text { in feces; therefore intestinal microbiota } \\
\text { effects are minimal. }\end{array}$ & $\begin{array}{l}\text { Rea et al. (2010) } \\
\text { Sullivan et al. (2001) }\end{array}$ \\
\hline Glycopeptides & Vancomycin & $\begin{array}{l}\text { Interferes with glycosylation of } \\
\text { the assembled peptidoglycan } \\
\text { polymer after transport to the cell } \\
\text { membrane. }\end{array}$ & $\begin{array}{l}\text { Loss of C. leptum, C. coccoides, C. } \\
\text { symbiosum, P. luminescens. Decrease in } \\
\text { Firmicutes, Bacteroidetes, Clostridiaceae, } \\
\text { Bacteroidaceae, Porphyromonadaceae, } \\
\text { Clostridium, and Odoribacter. } \\
\text { Increase in Proteobacteria, Enterobacte- } \\
\text { riaceae, Streptococcaceae, Lactococcus, } \\
\text { Sutterella, and Desulfovibrio. }\end{array}$ & $\begin{array}{l}\text { Rea et al. (2011) } \\
\text { Yap et al. (2008) } \\
\text { Murphy et al. (2013) }\end{array}$ \\
\hline
\end{tabular}


specifically the final cross-linking stage of the peptidoglycan layer (Page, 2012; Tipper, 1979; Strominger and Tipper, 1965). $\beta$-Lactams demonstrate broad-range activity against gram-negative and gram-positive bacteria (Holten and Onusko, 2000). Discovered in 1928 by Alexander Fleming, in 1940 penicillin was the first antibiotic to be produced in a large scale and is accredited with having saved millions of wounded during World War II. However, before its discovery the first $\beta$-lactamase was identified in 1940 in E. coli (Abraham and Chain, 1940), which was countered by the first $\beta$-lactamase inhibitor (clavulanic acid) in 1976. Clavulanic acid, along with amoxicillin, now forms part of Augmentin (Foulstone and Reading, 1982). After the first $\beta$-lactamase there have been many challenges to the success of $\beta$-lactams. Carbapenemases, classified as either molecular class B (metallo- $\beta$-lactamases), A, or D (serine carbapenemases, also known as oxacillinases) form three of the four known classes of $\beta$-lactamases (Miriagou et al., 2010). The host of specific carbapenemases varies depending on class. Metallo- $\beta$-lactamases are disseminated mainly in P. aeruginosa, but also Acinetobacter baumanii, Enterobaceriaceae, and Klebsiella pneumonia (Queenan and Bush, 2007, Walsh, 2008). K. pneumonia is the most common host of class A carbapenems (Queenan and Bush, 2007), although there have been reports of its occurrence in other species such as Klebsiella oxytoca, Salmonella enterica, E. coli, Enterobacter species, and Pseudomonas species (Queenan and Bush, 2007, Deshpande et al., 2006; Navon-Venezia et al., 2006; Villegas et al., 2007; Bennett et al., 2009). Oxacillinases (class D) are common in A. baumanii (Queenan and Bush, 2007). Most recently, the emergence of New Delhi metallo$\beta$-lactamase-1 in 2008, which has since spread worldwide, has transformed mildly pathogenic bacteria into lethal MDR bacteria (Rolain et al., 2010). The prevalence of metallo- $\beta$-lactamases in $P$. aeruginosa is of significant clinical concern given the importance of $P$. aeruginosa in CF lung exacerbations. Metallo- $\beta$-lactamaseproducing $P$. aeruginosa have shown an increase in the last 10 years and have been implicated in septicemia and pneumonia (Kouda et al., 2009; Gutiérrez et al., 2007; Pitout et al., 2007; Lagatolla et al., 2006). Extended spectrum $\beta$-lactamases (ESBLs) present another challenge to the treatment of gram-negative infections and are the main source of hospital- and community-acquired infections (Pitout and Laupland, 2008). Mainly arising in Enterobacteriaceae such as E. coli and Klebsiella species, ESBLs have plasmid encoded capability of hydrolyzing the $\beta$-lactam ring of the oxyimino-cephalosporins (cefotaxime, ceftriaxone, and ceftazidime) and monobactams (aztreonam; Bush and Jacoby, 2010; Dortet et al., 2012). Cephamycins (cefoxitin) and carabapenems (imipenem and meropenem) retain their activity against ESBLproducing bacteria. Reassuringly, in some cases $\beta$-lactamase inhibitors such as clavulanic acid and tazobactam still have the ability to inhibit ESBLs (Bush and Jacoby, 2010).

Bacteroides, Blautia, and Faecalibacterium species have been shown to increase in a study of four adults after a single antibiotic treatment with $\beta$-lactams such as ampicillin, amoxicillin, cefazolin, and sulbactam (Perez-Cobas et al., 2013; Monreal et al., 2005). This bacterial profile has been shown to be associated with bactericidal agents but not bacteriostatic antimicrobials. The increase seen in the Bacteroides 
and Parabacteroides species may be explained by the presence of a high rate of $\beta$-lactamase-producing strains observed in these genera. In addition, high levels of $c f i A$ gene identified suggest these strains act as reservoirs for antibiotic resistance genes and the common occurrence of cepA gene, which is responsible for production of cephalosporinases and penicillinases (Nakano et al., 2011; Wybo et al., 2007). Morotomi et al. (2011) also reported a dominance of Enterococcus genus after a single $\beta$-lactam antibiotic treatment. Adamsson et al. (1999) show that compared with a macrolide treatment (clarithromycin), a $\beta$-lactam treatment showed reduced, although still significant, ecological impact on the anaerobic populations and less emergence of resistant strains after treatment. The reduced disruption to anaerobic populations was also noted by Stark et al. (1993). In addition, Perez-Cobas et al. (2013) have demonstrated the metabolic effects of $\beta$-lactams in the alteration of bile acids, cholesterol, and hormones by intestinal bacteria. They showed a higher expression of genes related to energy metabolism during $\beta$-lactam treatment. This supports the hypothesis that long-term use of antibiotics undermines host-microbe mutualistic relationships.

\section{Lincosamides}

Clindamycin is a class of lincosamide antibiotics used to treat mainly anaerobic infections (Hedberg and Nord, 2002) with a bacteriostatic antimicrobial effect and a protein synthesis inhibitor mode of action. Resistance to clindamycin has increased significantly over the last two decades. Perez-Cobas et al. (2013) observed marked decreases in Bacteroides and Blautia genera immediately after administration; however, after 3 days a recovery of Bacteroides was observed, suggesting acquisition of resistance genes by these bacteria. They also noted that clindamycin induced an increase in Enterobacteriaceae compensating for loss of anaerobic bacteria. In comparison with other agents (fluoroquinolone or $\beta$-lactams) clindamycin was shown to result in a more variable and stronger effect on microbial community structure. Clindamycin has been shown to result in an increase in abundance of resistance genes, relative to other antibiotics such as moxifloxacin, amoxicillin, and cefazolin/ampicillin/sulbactam combination, mostly of the efflux pump class (Perez-Cobas et al., 2013).

\section{Fluoroquinolones}

Fluoroquinolones inhibit bacterial cell proliferation by inhibiting DNA gyrase and topoisomerase IV, both essential enzymes in bacterial DNA transcription and replication (Hooper, 2001). In addition to inhibiting these two enzymes, fluoroquinolones sequester these enzymes into a drug/enzyme/DNA complex that holds doublestranded DNA breaks together, blocking replication (Drlica, 1999). Treatment with different antibiotics from the fluoroquinolone class presents a similar initial response in the gut microbiota. Moxifloxacin showed a decrease in Faecalibacterium and Bacteroides, with ciprofloxacin showing similar effects with additional decreases seen in Lachnospiraceae and Ruminococcaceae (Perez-Cobas et al., 2013; Dethlefsen and Relman, 2011). Earlier fluoroquinolones such as ciprofloxacin, levofloxacin, 
norofloxacin, and orofloxacin target aerobic bacteria, mainly gram negatives, but similar to moxifloxacin, a methoxyquinolone, they result in a reduction in numbers of Enterobacteriaceae. Moxifloxacin has a wider reaching activity than the others with activity against respiratory pathogens, including $\beta$-lactamase-producing aerobic gram-positive cocci; Haemophilus and Moraxella; aerobic gram negatives; and intracellular and atypical microorganism such as Legionella, Chlamydia, and Mycobacterium. Moxifloxacin also has activity against gram-positive and gram-negative anaerobes. In a study looking at the effects of repeated courses of oral ciprofloxacin ( $500 \mathrm{mg}$ twice daily for 5 days at 2 - and 8 -month time points in a 10 -month study) and the disturbance to the gut microbiota in three subjects, Dethlefsen and Relman (2011) showed an almost complete return to the pre-ciprofloxacin state after the first treatment; however, after a second treatment the microbiota community composition was different from what it had been at the start of the study and appeared to be stable in its new state. Edlund et al. (2000) also showed significant decreases of enterococci, enterobacteria, bifidobacteria, and clostridia during moxifloxacin treatment (400 mg oral administration once daily for 7 days).

An interesting feature of fluoroquinolones is their ability to bind reversibly to bacteria and fecal material, resulting in reduced amounts of the drug in the intestine, translating to less disturbance of the total microbial intestinal population by fluoroquinolones (Edlund et al., 2000; Lidbeck et al., 1988). Because of this, moxifloxacin has a more targeted effect on the gut microbiota with more limited ecological disturbances (Edlund et al., 2000).

\section{Polmyxins}

Colistin sulfomethate is cyclopeptide, belonging to the family of polymyxins, which is produced by Bacillus polymyxa var. colistinus (Jeong et al., 2009; Storm et al., 1977). Colistin is mainly active against gram-negative organisms. Its mode of action involves inducing changes in the permeability of the cell wall by binding anionic lipopolysaccharide molecules and displacing calcium and magnesium, thus causing cell leakage and death (Jeong et al., 2009). Orally administered colistin is known to be poorly absorbed in the gastrointestinal tract, and studies show that when excreted it is bound to the fecal material (Eichenwald and McCracken, 1978). This may reduce the perturbation effect of the drug in vivo. Jeong et al. (2009) show that $E$. coli was the most susceptible to colistin. Colistin sulfomethate is one of the most frequently used antibiotics for treatment of exacerbations in CF patients. Early eradication of Pseudomonas infection with nebulized drug, aggressive treatment of acute exacerbations with intravenous therapy, and longterm suppressive maintenance therapy again nebulized are the three primary modes of usage in CF management. Colistin forms part of each of these (Littlewood et al., 2000). P. aeruginosa is known to frequently develop resistance to $\beta$-lactam antibiotics and aminoglycosides. However, thus far in vitro resistance of Pseudomonas species to colistin is rare, cementing its place as a useful treatment for pseudomonal infections for the foreseeable future. Wright et al. (2013) have shown using in vitro culture methods that antibiotics (ceftazadime, colistin, azithromycin, and 
tobramycin) at subinhibitory concentrations result in the phenotypic population diversification of $P$. aeruginosa. It is interesting to note that they demonstrated that ceftazadime and colistin contributed to more diversification than tobramycin and azithromycin. Diversification of the $P$. aeruginosa populations in the $\mathrm{CF}$ lung negatively affect antibiotic therapy success, leading to a chronic infection state and ultimately to progression of the disease. Whether this diversification pressure is also exerted on taxa in the gut has not been reported. Knowledge of differential diversification potential of antibiotics can contribute to more informed decisions for antibiotic selection in management and control of infection.

\section{Nitrimidazoles}

Metronidazole is the prototype of the nitroimidazole family and most widely used for treatment of anaerobic and protozoal infections (Lamp et al., 1999). Along with fidomoxacin and vancomycin, metronidazole is the mainstay of $C$. difficile treatment (Surawicz et al., 2013; Cornely et al., 2014), estimated to have colonized up to 50\% of CF patients (Binkovitz et al., 1999; Bauer et al., 2014). Metronidazole is known to have activity against gram-negative (Bacteroides fragilis) and gram-positive $(C$. difficile) anaerobes (Lofmark et al., 2010). Metronidazole functions by entering the cell in its inactive or prodrug state, becoming activated in the bacterial cytoplasm through an electron transfer to the nitro group of the drug, or protozoa organelles, to a cytotoxic state with DNA-binding capabilities. Inhibition of DNA synthesis and DNA damage by oxidation leads to DNA degradation and cell death (Land and Johnson, 1999; Diniz et al., 2000; Lofmark et al., 2010). Its activity is limited to anaerobic bacteria because aerobes lack the appropriate transfer proteins, conferring them with intrinsic resistance to metronidazole (Reysset, 1996). Mechanisms of resistance to metronidazole are primarily based on either decreased uptake of the prodrug or reduced electron transfer capabilities (Land and Johnson, 1999). Nitroimidazole (nim) resistance genes encode an alternative reductase protein that converts nitroimidazole to a nontoxic derivative, thus avoiding DNA damage (Reysset, 1996; Leiros et al., 2004; Lofmark et al., 2010). Metronidazole resistance is generally low, although there have been reports of resistance in Sutterella species (Jousimies-Somer et al., 2002). C. difficile maintains its susceptibility to metronidazole with no significant clinical resistance observed (Lofmark et al., 2010; Terhes et al., 2014). In a study using high-throughput sequencing, Rea et al. (2011) demonstrated phylum (reduction of Firmicutes and Bacteriodetes and increase of Proteobacteria) and family (increasing Enterobacteriaceae) effects of administering metronidazole in a colonic model experiment. The concentration of metronidazole in feces is low as a result of efficient absorption; therefore alterations to the normal microbiota after metronidazole treatment are minimal (Sullivan et al., 2001). Nagy and Foldes (1991) propose a mechanism of inactivation of metronidazole by intestinal enterococci, thus reducing its effect on the gastrointestinal microbiota. The success of oral metronidazole in Clostridium difficile infection (CDI) treatment is a result of the elevated plasma serum levels that diffuse through the damaged intestinal mucosa of infected individuals with greater efficiency (Sullivan et al., 2001). 


\section{Glycopeptides}

Glycopeptide antibiotics have an inhibitory mode of action on late-stage peptidoglycan polymer synthesis. Glycopeptide antibiotics interfere with glycosylation of the assembled peptidoglycan polymer after transport to the cell membrane (Reynolds, 1989). Vancomycin, teicoplanin, and most recently telvancin are the only glycopeptide antibiotics approved by the US Food and Drug Administration (FDA; Van Bambeke et al., 2004, Damodaran and Madhan, 2011). Glycopeptides are active against most gram-positive organisms but few gram-negative organisms. Vancomycin remains the first-line drug against methicillin-resistant Staphylococcus aureus (MRSA); however, emergence of resistance in enterococci and staphylococci has led to a restriction in the use of vancomycin as well as teicoplanin (Van Bambeke et al., 2004; Damodaran and Madhan, 2011). Yap and colleagues showed the disturbance effect of vancomycin on the gut microbiota in mice using a $2 \times 100 \mathrm{mg} / \mathrm{kg}$ per day dose for 2 days. Clostridium leptum, Clostridium coccoides, Cenarchaeum symbiosum, and Photorhabdus luminescens were lost immediately after treatment, with subsequent rapid recovery of $C$. leptum and $C$. coccoides. In an environmentally controlled 24-h model distal colonic experiment, Rea et al. (2011) showed a decrease in the major phyla, Firmicutes and Bacteroidetes, and an increase in Proteobacteria after addition of $90 \mu \mathrm{M}$ vancomycin at eight hourly intervals. The rapid proliferation of Enterobacteriaceae at the expense of other gram negatives and Firmicutes during vancomycin treatment is reported (Rea et al., 2011; Yap et al., 2008). In a dietinduced obesity mouse model administering $2 \mathrm{mg}$ /day vancomycin for 20 weeks, Murphy et al. (2013) attributed the decrease in Firmicutes and Bacteroidetes at the phylum level to a decrease in Clostridaceae and Bacteroidaceae at the family level, respectively, and increasing Proteobacteriaceae was attributed to increasing Enterobacteriaceae. At the family level they also noted decreases in Porphyromonadaeae and increases in Streptococcaceae and Desulfovibrionaceae, whereas at the genus level increases in Lactococcus, Sutterella, and Desulfovibrio and decreases in Clostridium and Odoribacter were observed.

\section{Effects of Combination Therapy on Gut Microbiota}

Combination or multidrug therapy often confers advantages over single drug therapy in terms of a wider range of targets, synergistic effects, reduction of MDR organisms, and reduction in total amount of antibiotic used; however, it incurs high costs, complications for administration, and drug-related toxicity (Elphick and Tan, 2005; Perron et al., 2012; Gould and van der Meer, 2007). Taylor et al. (1993) reported that $80 \%$ of clinics had preference for combination therapy. Combinational antibiotic therapy poses challenges to identifying, quantifying, and comparing the specific effects of antibiotic classes on the gut microbiota. At present, treatment of $P$. aeruginosa infection in patients with CF involves two to three antibiotics, demonstrating improved synergy (Zebouh et al., 2008; Hewer and Smyth, 2014). In general, this may include the use of inhaled antibiotics such as tobramycin and colistin (Littlewood and Macdonald, 1987, Ratjen et al., 2001), oral quinolones such as ciprofloxacin (Taccetti et al., 2005), and intravenous antibiotics usually involving a $\beta$-lactam antibiotic in combination 
with an aminoglycoside antibiotic (Döring et al., 2000, Hewer and Smyth, 2014). Combination therapies are a commonly used approach for biofilm management, with the rationale that multiple antibiotics, with a range of individual targets can combine to help suppress or eradicate the varying antagonistic phenotypes present in the biofilm (Barraud et al., 2013). Colistin is known to be active against bacterial cells with low metabolic activity whereas tetracycline and ciprofloxacin are known to be active against metabolically active cells (Pamp et al., 2008; Herrman et al., 2010).

Conclusive results yielding specific guidelines for treatment of pulmonary exacerbations and delaying chronic $P$. aeruginosa infection in CF patients have yet to be reached on whether combinational or monotherapy is more effective because of a lack of studies testing combinational therapy options versus monotherapy in a headto-head manner with control for confounding factors. Of the studies available, it is difficult to unequivocally indicate which is the most effective because studies differ in length of administration of antibiotic, age, health status and history of patient cohort; differing times from detection to initiation of treatment; frequency of surveillance; markers of success; and statistical analysis. However, the current physician consensus infers a preference for combinational therapy for patients with $\mathrm{CF}$ (Elphick and Tan, 2005).

\section{LONG-TERM ISSUES OF CHRONIC ANTIBIOTIC USE MULTIDRUG RESISTANCE}

Almost immediately after the introduction of the first antibiotics, a parallel emergence of resistance has inhibited their success (Davies and Davies, 2010). Most recently, a World Health Organization report on antimicrobial resistance (AMR) (2014) warns of the dangers of entering a postantibiotic era in which minor infections could emerge as life threatening diseases in the face of an AMR pandemic. MDR is a major public health issue facing the medical and wider community (Laxminarayan et al., 2013). In the European Union (EU), AMR is estimated to be responsible for 25,000 deaths each year, whereas health-care-related costs are estimated to be $€ 0.9$ billion with a further $€ 1.5$ billion expenditure on productivity losses (Rodier, 2011; Report EEJT, 2009). MDR is compromising our ability to manage infectious disease. Welldocumented MDR organisms include P. aeruginosa and Burkholderia cepacia complex, as well as emerging methicillin-resistant Stenotrophmonas maltophilia and MRSA. MDR was responsible for 23,000 deaths in the United States in 2013, of which MRSA and Streptococcus pneumoniae were responsible for 11,000 and 7000 deaths, respectively (CDC, 2013). Antibiotic overuse and misuse is the driving force of the development of resistant organisms (Laxminarayan and Heymann, 2012). An empirical strategy of treatment based on expert consensus remains the mode of action on diagnosis of pulmonary exacerbation. This generalized treatment strategy inevitably contributes to the adverse effects of antibiotic overuse in terms of dose and time. This is compounded by the increase in age of the CF demographic 
(Waters and Ratjen, 2006) globally (CFRI Annual report 2011; Davis, 2006; www. cff.org), with the ratio of adult CF patients to pediatrics increasing each year.

The human gastrointestinal tract is an environment where $10^{13}-10^{14}$ microorganisms are in constant interaction, providing an ideal situation for rapid dissemination of resistance genes between commensals and pathogens (Salyers et al., 2004; Davies, 1994). The human gut microbiota is now viewed as a reservoir where commensals and pathogens are in direct contact, thus facilitating the spread of resistance genes (Salyers et al., 2004; Sommer et al., 2009; Fouhy et al., 2014). Studies have established that the gut resistome is established in infancy, even in the absence of antibiotic therapy, growing and diversifying with age (Fouhy et al., 2014). In response to antibiotic therapy, resistance genes are expressed and selected, with strains carrying resistance proliferating, amplifying the resistance reservoir (Lu et al., 2014; Fouhy et al., 2014). In CF patients, or other groups on chronic antibiotic therapy, the resistome is likely to have increased capabilities. Whole genome sequencing has shown that lateral gene transfer and mobilizable elements that incorporate into various host bacteria are responsible for most resistance (Ochman et al., 2000). Transferable resistance genes may arise in commensals and through lateral gene transfer mechanisms spread to clinically relevant pathogenic strains. It is postulated that the gut microbiome may facilitate the acquisition of resistance by pathogenic strains (Sommer et al., 2009). Sommer et al. (2009) used a functional metagenomic approach to characterize the antibiotic resistome of two healthy unrelated humans who had not been treated with antibiotics for a least 1 year. Phylogenetic profiling of aerobically cultured strains from the gut microbiome showed they were primarily members of the Proteobacteria phyla and to a lesser extent Firmicutes and Actinobacteria. Resistance genes belonging to one of the following classes - tetracycline efflux pumps, two classes of aminoglycoside-modifying enzymes, and three classes of $\beta$-lactam-inactivating enzymes (TEM, AmpC, and CTX$\mathrm{M}$ ) - were detected. Characterizing the human gut resistome may increase understanding of the origin of the antibiotic resistance, ultimately addressing the MDR issue.

The expression and subsequent persistence of resistance genes ensuing antibiotic treatment varies depending on antibiotic class, duration, and dose strength of treatment. Persistence of resistance may be observed years after an antibiotic course. For instance, after a 5-day antibiotic treatment (500 mg twice daily) with ciprofloxacin, initial gut microbiota perturbations recover; however, resistance to the particular antibiotic is enriched and may be observed for months or even years afterwards (Dethlefsen et al., 2008). Likewise, Sjölund et al. (2003) showed that in three of five patients post-clarithromycin treatment, erythromycin resistance was present after 1 year and in one patient after 3 years. Jernberg et al. (2007) also showed the persistence of resistance genes ( $\mathrm{ermF}$, erm $\mathrm{e}$, and $\mathrm{ermB})$ after clindamycin treatment up to 2 years after a 7-day antibiotic treatment. Shoemaker et al. (2001) demonstrated that the presence of the tet $Q$ gene has increased from $30 \%$ to $80 \%$ in all strains of Bacteroides as a result of conjugal gene transfer in the last three decades.

Some genera may contribute to multidrug resistance more than others by acting as a reservoir for mobilizable resistance determinants. Bacteroides and Parabacteroides species are mutualistic inhabitants of the gut performing many beneficial 
functions for the host, such as carbohydrate metabolism (Xu et al., 2003). Bacteroides form $25 \%$ of the adult human gut microbiota (Salyers, 1984) and have been implicated in many opportunistic infections, particularly B. fragilis (Wexler, 2007; Cao et al., 2014). They have an innate ability to produce $\beta$-lactamases such as cephalosporinases and penicillinases encoded by the cepA gene (Gutacker et al., 2000). Clindamycin resistance, encoded by the $\mathrm{ermF}, \mathrm{erm} B$ or $\mathrm{erm} G$ genes or through efflux pumps, in Bacteriodales ranges from $10 \%$ to $42 \%$ and confers protection against macrolides, lincosamides, and stretogramin B (Wybo et al., 2007; Gupta et al., 2003; Nakano et al., 2011; Shoemaker et al., 2001; Pumbwe et al., 2007). In a study by Nakano and colleagues (2011), 53.5\% of tested Bacteroides and Parabacteroides strains were tetracycline resistant, primarily because of the acquisition of the tet $Q$ ribosome protection protein. The rise of resistance genes in predominating and functionally vital genera of the human gastrointestinal tract provide pathogens with increased opportunity for acquisition of many resistance determinants.

AMR rates are increasing and studies such as the SMART (Study for Monitoring Antimicrobial Resistance Trends), PROTEKT (Prospective Resistant Organism Tracking and Epidemiology for the Ketolide Telithromycin), and SENTRY (an international, longitudinal study on the susceptibility of pathogens sponsored by Bristol Meyers Squibb) seek to globally monitor and characterize AMR rates (Morrissey et al., 2013). The SMART study describes the increase in prevalence of ESBLs, conferring resistance to $\beta$-lactams, in Asia, Europe, Latin America, Middle East, North America, and the South Pacific. The study also reports the increasing resistance to fluoroquinolones, particularly in P. aeruginosa (increases from $22 \%$ to $33 \%$ were seen in North America). Macrolide resistance rates have also been shown to be increasing (Cresti et al., 2002). Recent studies have indicated this is due to the epidemic spread of ermB resistance genes among streptococcal populations and in particular Streptococcus pyrogenes, either by horizontal gene transfer or clonal expansion of resistant isolates after selective pressures of antibiotic treatment (Jakobsson et al., 2010). Sjölund et al. (2003) have reported the presence of macrolide-resistant enterococci after selection by clarithromycin and metronidazole.

\section{Development of Opportunistic Pathogens and Antibiotic-Associated Diarrhea}

Chronic antibiotic therapy results in significant alterations in the gut microbiota, creating opportunities for opportunistic pathogens, primarily $C$. difficile, to establish and proliferate. $C$. difficile is mostly a nosocomical infection of the elderly, but it can also be community acquired, affecting younger populations and adults. The CDC has linked $C$. difficile to 14,000 deaths in America (CDC, 2013). The European Center for Disease Control estimates that CDI costs the EU €3 billion per year (ECDC, 2015). Broad-spectrum antibiotic therapy has been associated with increased incidence of $C$. difficile and is identified as one of the most well-recognized risk factors for C. difficile and indeed recurrent and refractory CDI (Bartlett and Gerding, 2008; Diggs and Surawicz, 2009). Broad-spectrum antibiotics induce a dysbiotic gut microbiota, particularly among anaerobic populations, providing $C$. difficile with an opportunity to proliferate. Indeed, Owens et al. (2008) reported $94 \%$ of hospitalized patients with 
CDI had received antibiotics before or during their hospital stay. C. difficile is responsible for $20-25 \%$ of AAD cases and $90-100 \%$ of pseudomembraneous colitis (Rea et al., 2010; Cramer et al., 2008). Ironically, antibiotic treatment of CDI perpetuates its proliferation, increasing strains resistant to vancomycin, particularly enterococci (Chang et al., 2008), lowering diversity and providing C. difficile with opportunity to proliferate. The association between ampicillin, cephalosporins, and fluoroquinolones and CDI is well recognized in the literature (Gerding, 2004; Sullivan et al., 2001). It is interesting to note that the emergence of particular antibiotics as risk factors for CDI has paralleled the frequency of that particular antibiotic class in general medical use. The increase of CDI was initially associated with clindamycin, which is the preferential treatment for various anaerobic, streptococcal, and Staphylococcus infections. Since the 1990s, the increase in the use of fluoroquinolones to treat various infections has precipitated these antibiotics in becoming risk factors for CDI and has contributed to the emergence of hypervirulent strains such as ribotype 027 , which is characterized by fluoroquinolone resistance, binary toxin production, and increased toxin production due to a mutation in the $t c d C$ gene (Pepin et al., 2005; Kuijper et al., 2008). Metronidazole and vancomycin have also been determined as risk factors for CDI. In cases in which antibiotics are necessary to treat concomitant infection, alternative antibiotics to those identified as CDI development risk factors should be used where possible. As expected, increased duration of antibiotic courses and antibiotic combination therapy are associated with increased risk of CDI (Owens et al., 2008). Not all antibiotics for CDI infection are associated with increased risk. Piperacillin in combination with tazobactam has shown considerable success in treatment of CDI but with less associated risk of increased development of infection or relapse (Owen et al., 2008). Vancomycin and, more recently, fidaxomicin (2011) are the only drugs approved by the FDA for CDI treatment. Fidaxomicin is particularly effective in treating recurrent CDI because it has less impact on the fecal microbiota, translating into a more resilient microbial assemblage after treatment. Fidaxomicin shows less risk of development of resistance than vancomycin in in vitro studies (Zar et al., 2007). Alternative therapies that may facilitate the reduction of antibiotics are necessary to treat CDI. These include fecal microbial transplant (FMT), which is an alternative therapy at conceptual stage with early pioneering case studies showing considerable success in patients with reoccurring symptomatic $C$. difficile (Petrof et al., 2013; Koenigsknecht and Young, 2013). Another alternative includes thuricin CD, a novel antimicrobial peptide (AMP) or bacteriocin produced by Bacillus thuringiensis, which has been patented as a CDI therapy (Rea et al., 2010). The potency of thuricin CD has been shown to be greater than vancomycin and in some cases greater than metronidazole. In addition, thuricin $\mathrm{CD}$ shows no antimicrobial activity against a range of commercially available probiotics, demonstrating its narrow substrate range (Rea et al., 2011).

Asymptomatic carriage of $C$. difficile in $\mathrm{CF}$ is well recognized; however, the mechanisms of protection against infection, but not colonization, are not fully understood. Carriage rates in healthy adults vary from $0 \%$ to $15 \%$ (Viscidi et al., 1981; Nakamura et al., 1981), compared with up to $50 \%$ in CF cohorts-a result of prophylaxis and frequent hospitalizations. However, unlike normal populations in which 
approximately $50 \%$ of colonized individuals develop CDI, or in more severe cases pseudomembranous colitis, development of response to $C$. difficile toxins is rare in CF patients (Kyne et al., 2000; Peach et al., 1986; Welkon et al., 1985). It is hypothesized that the unique microbial assemblage of CF patients with high levels of Enterbacteriaceae, lactobacilli, Pseudomonas, and Staphylococcus confers protection and resistance against $C$. difficile growth, but not colonization (Rolfe et al., 1981). Welkon et al. (1985) suggest an altered gut $\mathrm{pH}$ as a result of defective ion transport inhibits toxin production or degrades toxins, although there is no evidence to support this. Another possibility postulates that exposure to $C$. difficile at such an early age mediates an immune response that protects in later life (Welkon et al., 1985). The relatively low incidence of CDI despite high rates of toxigenic $C$. difficile colonization and antibiotic usage is an area of much needed research.

Metagenomic studies in cohorts with Clostridium difficile-associated diarrhea (CDAD) that have investigated microbiome shifts noted increases in C. difficile and Bacteroidetes, C. coccoides, Eubacterium rectale, Ruminococcus gnavus, and Clostridium nexile (Chang et al., 2008). It is interesting to note that the Bacteroidetes phylum seems to show a strong association with CDAD in several studies. Manges et al. (2010) show that low levels of Bacteroidetes are associated with CDAD. Tvede and Rask-Madsen (1989) demonstrate using bacteriotherapy experiments that the absence of Bacteroides species such as Bacteroides ovatus, Bacteroides vulgaricus, and Bacteroides thetaiotaomicron may result in recurring CDI whereas their abundance in the gut microbiota may afford protection against colonization and proliferation against $C$. difficile. Low Firmicutes and Bacteroides ratios, along with increasing facultative anaerobes, have been shown to be associated with $C$. difficile colonization in infants (Rousseau et al., 2011). Metagenomic studies of patients with CDI noted a decrease in alpha diversity at the DNA level (Chang et al., 2008; Knecht et al., 2014). However, Knecht et al. hypothesize that instead of a microbiota-wide compositional change, a loss of functionality of a single species may impair the resilience of the microbiota to $C$. difficile colonization. These functions may include short-chain fatty acids (SCFAs) or antimicrobial production, which may protect against $C$. difficile proliferation. Recent research by Knecht et al. (2014) indicates that Lachnospiraceae may be one such species in which low or high levels are associated with protection against or colonization with $C$. difficile.

Antibiotic substitutions for other options with less risk of CDI development associated may be effective (Vonberg et al., 2008). Further research into drug development is warranted to provide options that cause less disruption to the microbiota, consequently affording $C$. difficile less opportunity to proliferate.

\section{Interference of Mutualistic Host-Microbe Interactions through Antibiotic- Induced Alteration of Gut Microbiome}

The human intestinal microbiota develops a partnership with the host and is essential to health and functions such as nutrition, immunoregulation, metabolism, development, and pathogen resistance. With approximately 100 times more genes than the human genome, the gut microbiome lends us functional features we have not had to 
evolve ourselves (Backhed et al., 2005). Although the intestinal community does seem to have a level of taxonomic functional redundancy, antibiotic-mediated elimination or significant reduction of important members of the microbiota is likely to affect functionality and host physiology, particularly in the case of chronic antibiotic therapy (Perez-Cobas et al., 2013). Many key species of the human intestinal microbiota perform important functions; however, disruption of the core gut colonizers by antibiotic therapy may have a more profound effect on the functioning of the microbiota as a symbiotic partner of the host. Examples include B. thetaiotaomicron, a prominent mutualist in the intestinal microbiome, which has a genome-encoded capacity for carbohydrate metabolism far greater than the carbohydrate-metabolizing capabilities of our human genome (Shipman et al., 2000; Backhed et al., 2005). The gut microbiota also functions in regulation of bile acid and choline metabolism. The gut microbiota ecosystem comprises a dynamic network of functional interactions. As in any ecosystem, even targeted, or narrow-spectrum antibiotic effects will influence not only the target but also indirectly affect many interaction partners (Willing et al., 2011). Antibiotic therapy can induce host immunity effects through the loss of bacterial ligands, metabolites, and specific bacterial signals (Willing et al., 2011). Receptors involved in host immunity, such as toll-like receptors and NOD-like receptors are activated by specific bacterial ligands such as lipopolysaccarhide, lipoteichoic acid, flagellin, and peptidoglycan. The loss of specific bacterial ligands reduces immune signals (Wells et al., 2011). Metabolic profiles of antibiotic-treated mice show a reduction of SCFAs, with downstream reduction in the antiinflammatory effects of SCFAs as well as functions in regulation of cell proliferation, differentiation, growth, apoptosis, vasodilation, and wound healing (Yap et al., 2008; Millard et al., 2002; Leung et al., 2009; Bergman, 1990). Populations of bacteria have specific signals associated with them that may be lost after antibiotic treatment. In addition, many studies report reduced expression and secretion of AMPs, directly affecting first-line microbial defense (Meyer-Hoffert et al., 2008). Taken together, these factors result in a host more susceptible to pathogen insult (Willing et al., 2011).

The diversity of the human gut microbiota is the result of natural selection at the microbial level and the host level (Backhed et al., 2005). Diversity confers resilience to stress, such as antibiotic therapy, by harboring a diverse range of responses. This is known as the insurance hypothesis (Guarner, 2007). In general, low diversity correlates with poor health status (Lozupone et al., 2012; Claesson et al., 2012). This is one of the primary caveats of gut health and is demonstrated in infants, adults, and elderly populations. Many disease states have been associated with low-diversity microbiota signatures in recent years. Antibiotics as agents drive the microbiota to an altered assemblage through a gradual drift or dramatic shift, which may lead to the onset of microbiota-related diseases associated with less diversity, such as obesity (Turnbaugh et al., 2006), diabetes (Larsen et al., 2010), and inflammatory bowel disease (IBD; Dicksved et al., 2008). Turnbaugh et al. (2006) demonstrated that colonization of germ-free mice with "obese" microbiota resulted in development of obese phenotype and likewise in lean mice. Childhood antibiotic use and the resulting altered microbiota are potentially associated with asthma, atopic disease and obesity 
(Marra et al., 2006; Noverr and Huffnagle, 2005). Low gut microbiota diversity in infants has been associated with eczema (Abrahamsson et al., 2012), particularly of the phylum Bacteroidetes and its genus Bacteroides. Indeed, in a study of 123 CF children, 59\% presented with skin hypersensitivity allergy (Warner et al., 1976). Although not proposed by the authors at the time, low-diversity gut microbiota may have contributed to the hypersensitivity observed. The reduction of gut microbiota diversity after exposure to antibiotics is well documented. Antibiotic exposure may reduce overall diversity and/or diversity of select taxonomic groups, as seen by Jernberg et al. (2007) in a study of four patients exposed to $150 \mathrm{mg}$ clindamycin 4 times daily. They observed an overall reduction in gut microbiota diversity but also a reduction in diversity of the Bacteroides community and emergence of clindamycin-resistant strains. In a study investigating the effects of ciprofloxacin $(500 \mathrm{mg}$ twice daily for 5 days) on the gut microbiota of adult patients, the abundance of one-third of bacterial taxa were reduced (Dethlefsen and Relman, 2011). Likewise, Rea et al. (2010) showed reduction of diversity after exposure to metronidazole and vancomycin in a human colonic model, mostly accounted for by the proportional increase of Enterobacteriaceae. However, despite the well-acknowledged effect of the lack of diversity on host health, the functional redundancy and resilience of the gut microbiota is also accepted. Indeed, Dethlefsen et al. (2008) have demonstrated that although the gut microbiota was disturbed after treatment with ciprofloxacin, they observed a continuity of microbial functions. It remains to be investigated whether the low-diversity microbiota disorders described could be the result of perturbations brought about by antibiotics alone or a combination of factors in which antibiotic therapy is perhaps the factor that tips the balance to a disease state.

The hygiene hypothesis is quoted frequently as an argument against sterilizing our environment and indeed our bodies through antibiotic use (Wills-Karp et al., 2001). The increasing incidence of autoimmune disorders such as asthma, eczema, celiac disease, and IBD may be related to disruption of normal host-microbe interactions by antibiotics (Guarner et al., 2006). Guarner hypothesizes that deficient exposure to mutualistic bacteria such as bifidobacteria and lactobacilli explains the increase of immunodysregulatory disorders in modern society. Guarner proposes the use of prebiotics and probiotics as a more favorable method of infection control.

\section{MODULATION OF THE GUT MICROBIOTA}

\section{DIET}

Diet has rapid and profound modulatory effects on the gut microbiota composition and functionality. Various diet types, including high-fat, high-sugar, "Western," and low-fat, polysaccharide-rich diets, have been associated with microbiota signatures differing at the compositional and functional gene level. Particular bacterial species have genetically encoded specific metabolic capabilities. The gut microbiota adapts to dietary intake to select bacterial populations with the genetic capabilities best suited 
for metabolism substrates of a given diet (Scott et al., 2008; Power et al., 2014). The rapid response of the gut microbiota to changes in diet has been demonstrated by studies in conventionalized germ-free mice. A change from a low-fat/plant-rich diet to a high fat and sugar/low plant polysaccharides "Western diet" showed changes in the gut microbiota within a single day, with increases in Firmicutes and decreases in Bacteroidetes (Turnbaugh et al., 2009). Hildebrandt et al. (2009) showed a similar rapid response in the gut microbiota to a dietary change (high-fat/low-fiber or low-fat/high-fiber) within $24 \mathrm{~h}$. Most pertinent to CF are the effects of a high-fat diet on the gut microbiota composition. Dietary requirements for $\mathrm{CF}$ persons include $120-150 \%$ estimated average requirement of energy and $200 \%$ reference nutrient intake for protein (Littlewood and Macdonald., 1987; Pencharz and Durie., 1993). In addition, it is recommended that the CF total calorie intake should comprise $40 \%$ fat (White et al., 2004). The response of the gut microbiota to dietary fat is well documented. De Filippo et al. (2010) established the profound difference between the gut microbiota of European children on a typical Western diet (high fat, sugar, animal protein, and starch and low fiber content) and children in the African state of Burkina Faso, who consumed a predominantly vegetarian diet that was high in plant polysaccharides, starch, and fiber and low in animal protein and sugar. The Burkina Faso children had a lower abundance of Firmicutes and a higher abundance of Bacteroidetes genera (Xylanibacter and Prevotella), involving cellulose and xylan hydrolysis, enabling efficient energy extraction from their plant-rich diet. Indeed, a study by Wu et al. (2011) linked gut microbial enterotypes dominated by either Bacteroides or Prevotella with diets dominated by either protein and animal fat or carbohydrates along with low meat and dairy intake, respectively. A high-fat diet has been shown to influence a less diverse microbiota and a higher proportion of Bacteroidetes, Parabacteroides, Eubacterium, Anaerotruncus, Lactonifactor, and Coprobacillus in elderly subjects (Claesson et al., 2012). In the same study, community-dwelling subjects having a predominantly low to moderate fat intake had higher abundance of Prevotella, Coprococcus, and Roseburia. In addition to compositional microbial effects, a high-fat diet has been shown to result in a low-grade intestinal inflammatory state, which is a hallmark of CF (Arkan et al., 2005; Werlin et al., 2010).

Gastrointestinal manifestations of CF include exocrine pancreatic insufficiency (PI), steatorrhoea, intestinal inflammation, distal intestinal obstruction syndrome (DIOS) and cystic fibrosis-related diabetes (CFRD). PI occurs in 90\% of CF patients, resulting in malabsorption of fat; protein; and fat-soluble vitamins $\mathrm{A}, \mathrm{D}, \mathrm{E}$, and $\mathrm{K}$ and subsequent malnutrition (Fieker et al., 2011; Dodge and Turck, 2006). Undigested, unabsorbed dietary fat is excreted in stools, known as steatorrhoea (Somaraju and Solis-Moya, 2014) PI predisposes CF individuals to the onset of DIOS, an obstruction of fecal transit at the ileocecal junction (Somaraju and Solis-Moya, 2014). DIOS occurs in 10-20\% of patients because of increased water absorption as a result of defective intestinal CFTR. CFRD occurs in approximately $2 \%$ of children, $19 \%$ of adolescents, and $40-50 \%$ of adults presenting with CF. CFRD, distinct from the type I and type II diabetes found in the general population (Stecenko and Moran, 2010) is associated with poorer pulmonary function and nutritional status (Koch et al., 2001; 
Marshall et al., 2005). Although there is a paucity of information on how these gastrointestinal manifestations affect the intestinal microbiota, especially in the CF context, a microbiota response to such comorbidities is probable.

\section{Positive Modulation of the Gut Microbiota}

Positive modulation of the gut microbiota and host health can be achieved using probiotics, most commonly Lactobacillus or Bifidobacterium species. The beneficial effects of probiotics are perhaps more subtle than previously thought. Scientists are moving from a theory that probiotics alter total gut microbiome composition to a concept of prebiotics conferring a direct health benefit on the host (Power et al., 2014; Ouwehand et al., 2002). Thus far probiotics have been demonstrated to have therapeutic potential in treatment of AAD (Videlock and Cremonini, 2012; Hempel et al., 2012), CDI (Na and Kelly, 2011), IBD (Isaacs and Herfarth, 2008), and irritable bowel syndrome (Andersen and Baumgart, 2006). There have been preliminary but promising studies trialing administration of Lactobacillus rhamnosus GG (LGG) as a probiotic in pediatric CF cohorts. Bruzzese et al. (2004, 2014) showed the success of LGG in reducing intestinal inflammation as indicated by the noninvasive inflammatory markers nitric oxide and fecal calprotectin. The treated cohort also reported decreased abdominal pain. To further investigate the positive effects of LGG for the CF population, Bruzzese et al. (2007) investigated the effects of LGG administration on the rate of pulmonary exacerbation. They demonstrated a protective effect of LGG in children chronically infected with Pseudomonas and consequently a reduction in pulmonary exacerbations and increase in $\mathrm{FEV}_{1}$. Weiss et al. (2010) showed a significant reduction in pulmonary exacerbations in children with CF infected with $P$. aeruginosa after administration of a probiotic cocktail containing Lactobacillus acidophilus, Lactobacillus bulgaricus, Bifidobacterium bifidum, and Streptococcus thermophilus; $90 \%$ of patients were also receiving azithromycin treatment at the time. The offsite effects of Lactobacillus species on Pseudomonas in the lung suggest a direct effect between the former and the latter, supported by earlier studies in mice in which LGG administration reduced Pseudomonas species, and Lactobacillus plantarum showed inhibitory activity toward Pseudomonas species (Valdez et al., 2005). Bruzzese et al. (2014) showed partial recovery of gut microbiota in $\mathrm{CF}$ children on antibiotic treatment who were subsequently treated with LGG with a significant increase of Bacteroides and a trend toward an increase in $F$. prausnitzii, a known antiinflammatory agent.

Probiotic strains with antibiotic tolerance may have application after or during antibiotic therapy. However, antibiotic tolerance in probiotic bacteria is generally associated with safety concerns by food safety authorities such as the European Food Safety Authority (EFSA) because of the risk of dissemination of resistance determinants from probiotics to commensal or pathogenic members of the gastrointestinal microbiota. Plasmid or mobile genetic element mediated resistance carried by many probiotic genera poses a serious safety issue (Sharma and Singh Saharan, 2014). In addition, there are issues for antibiotic-probiotic combination therapy and possible resulting antagonistic relationships that may exist. Increased bacterial load due to the presence of viable probiotics may reduce the potency of antibiotics. It has been shown that 
the potency of vancomycin decreases depending on the numbers of bacteria exposed (Udekwu et al., 2009). Probiotic-antibiotic combinations that preserve the potency of the antibiotic and the viability of the probiotic must be selected (Hammad and Shimamoto, 2010). Antibiotic-tolerant probiotic therapies remain at the conceptual stage because of difficulty in determining safety. However, the potential for application in a cohort with chronic antibiotic usage warrants further research into this novel area.

Knowledge of which microbiota community composition resists change more efficiently may be important in probiotic development. It may be possible to direct microbial communities toward a more resilient assemblage in individuals for whom chronic antibiotic use is necessary. In the future, probiotics may provide an adjunct therapy along with antibiotics for the treatment of CF symptoms. The possibility of reduction of antibiotics through use of alternative therapies, such as probiotics, is attractive to patients and clinicians.

\section{FUTURE DIRECTIONS}

Antimicrobial discovery has been in decline since the 1970s, and MDR is an increasingly serious threat to global public health. As an immediate response to MDR we can curb the inappropriate use and overuse of antibiotics, gain knowledge on antibiotic effects, and administer at doses that target aberrant bacteria while beneficial bacteria are preserved, all of which can help preserve and maintain the effectiveness of antibiotics for the next generation. In this age of high-throughput, next-generation sequencing technologies, it is imperative that we use the technologies available to us to tailor the antibiotics currently available to the individual instead of the "catch-all" broadspectrum approach that has consequences on our antibiotic resources. CFMATTERS (Cystic Fibrosis Microbiome Derived Antimicrobial Therapy Trial in Exacerbations Results Stratified) is an EU-funded multicenter study currently examining this question in adult patients with CF (www.cfmatters.eu, https://clinicaltrials.gov/ct2/show/ NCT02526004). Alternative additional strategies dealing with infection need to be brought from the bench to mainstream clinical practice. There have been several studies investigating the use of bacteriophage as a therapeutic to treat $\mathrm{CF}$ lung infection, particularly in treating Pseudmonas infection, but also $S$. aureus and B. cepacia (Brussow, 2012; Debarbieux et al., 2010; Alemayehu et al., 2012, Morello et al., 2011). Phage therapy is advantageous over antibiotic therapy because of its specificity to the target pathogen, its ability to replicate at the site of infection, and its ability to evolve along with bacterial populations that may develop resistance. Alemayehu et al. (2012) have demonstrated the efficacy of a phage cocktail (a myovirus $(\phi \mathrm{NH}-4)$ and a podovirus (фMR299-2)) to clear murine Pseudomonas lung infection. Furthermore, it has been shown that phage not only cleared Pseudomonas infection but also prevented infection when administered $24 \mathrm{~h}$ before infection, highlighting a potential role of phage in prophylaxis (Debarbieux et al., 2010; Morello et al., 2011).

Inhibition of Pseudomonas virulence and biofilm formation through disabling quorum sensing networks is another potential therapeutic approach for infection 
control. O'Loughlin et al. (2013) have demonstrated the utility of a quorum sensing inhibitory molecule (meta-bromo-thiolactone) to block pathogenesis by interacting with the two major quorum sensing systems Lux I/R. In addition they demonstrated the potential for preventative and curative treatment using meta-bromo-thiolactone. Further work is needed in these areas.

\section{CONCLUSION}

The collateral consequences of antibiotic therapy on the gut microbiota have been widely studied, and it is accepted that chronic and/or long-term antibiotic use has compositional and potentially functional effects on the gut microbiota. In a cohort with chronic antibiotic usage, such as $\mathrm{CF}$, antibiotic resistance capabilities are expected to be high with consequences for subsequent antibiotic therapy. The long-term persistence of resistance genes in the gut microbiota in response to antibiotic therapy poses a concern for the clinical management of infection. Moving forward, tailored, individualized antibiotic strategies may prove critical along with additional options other than antibiotics. Phage therapy and targeting of quorum sensing networks may provide alternatives or adjunct therapies to antibiotic therapy in the future. Probiotics may be used as restorative agents to reintroduce depleted populations and maintain the gut microbiota ecosystem. In the interim, the medical community and wider society must endeavor to preserve our antibiotic resources through strategic and rational administration.

\section{ACKNOWLEDGMENTS}

The authors and their work are supported by the Science Foundation of Ireland (SFI)-funded Center for Science, Engineering and Technology; the APC Microbiome Institute; and in part by CFMATTERS. CFMATTERS has received funding from the EU's Seventh Framework Program (FP7/2007-2013) under grant agreement No. 603038.

\section{REFERENCES}

Abraham, E.P., Chain, E., 1940. An enzyme from bacteria able to destroy penicillin. 1988 July-August Rev. Infect. Dis. 10 (4), 677-678.

Abrahamsson, T.R., et al., 2012. Low diversity of the gut microbiota in infants with atopic eczema. J. Allergy. Clin. Immunol. 129 (2), 434-440, 440.e1-20.

Adamsson, I., Nord, C.E., Lundquist, P., et al., 1999. Comparative effects of omeprazole, amoxicillin plus metronidazole on the oral, gastric and intestinal microflora in Helicobacter pylori-infected patients. J. Antimicrob. Chemother. 44, 629-640.

Alemayehu, D., Casey, P.G., McAuliffe, O., Guinane, C.M., Martin, J.G., Shanahan, F., Coffey, A., Paul Ross, R., Hill, C., 2012. Bacteriophages $\phi \mathrm{MR} 299-2$ and $\phi \mathrm{NH}-4$ can eliminate Pseudomonas aeruginosa in the murine lung and on cystic fibrosis lung airway cells. MBio 3 (2), e00029-12. 
Amadori, A., et al., 2009. Recurrent exacerbations affect FEV(1) decline in adult patients with cystic fibrosis. Respir. Med. 103 (3), 407-413.

Andresen, V., Baumgart, D.C., 2006. Role of probiotics in the treatment of irritable bowel syndrome: potential mechanisms and current clinical evidence. Int. J. Probiotics Prebiotics $1(1), 11$.

Antonopoulos, D.A., et al., 2009. Reproducible community dynamics of the gastrointestinal microbiota following antibiotic perturbation. Infect. Immun. 77 (6), 2367-2375.

Arkan, M.C., Hevener, A.L., Greten, F.R., Maeda, S., Li, Z.W., Long, J.M., et al., 2005. IKK- $\beta$ links inflammation to obesity-induced insulin resistance. Nat. Med. 11 (2), 191-198.

Bäckhed, F., Ley, R.E., Sonnenburg, J.L., Peterson, D.A., Gordon, J.I., 2005. Host-bacterial mutualism in the human intestine. Science 307 (5717), 1915-1920.

Barraud, N., et al., 2013. Mannitol enhances antibiotic sensitivity of persister bacteria in Pseudomonas aeruginosa biofilms. PLoS One 8 (12), e84220.

Bartlett, J.G., Gerding, D.N., 2008. Clinical recognition and diagnosis of Clostridium difficile infection. Clin. Infect. Dis. 46 (Suppl. 1), S12-S18.

Bartosch, S., Fite, A., Macfarlane, G.T., McMurdo, M.E., June 2004. Characterization of bacterial communities in feces from healthy elderly volunteers and hospitalized elderly patients by using real-time PCR and effects of antibiotic treatment on the fecal microbiota. Appl. Environ. Microbiol. 70 (6), 3575-3581.

Bauer, M.P., Farid, A., Bakker, M., Hoek, R.A.S., Kuijper, E.J., Dissel, J.T., 2014. Patients with cystic fibrosis have a high carriage rate of non-toxigenic Clostridium difficile. Clin. Microbiol. Infect. 20 (7), O446-O449.

Bennett, J.W., Herrera, M.L., Lewis, J.S., Wickes, B.W., Jorgensen, J.H., 2009. KPC-2producing Enterobacter cloacae and Pseudomonas putida coinfection in a liver transplant recipient. Antimicrob. Agents Chemother. 53 (1), 292-294.

Bergman, E.N., 1990. Energy contributions of volatile fatty acids from the gastrointestinal tract in various species. Physiol. Rev. 70 (2), 567-590.

Binkovitz, L.A., Allen, E., Bloom, D., Long, F., Hammond, S., Buonomo, C., Donnelly, L.F., 1999. Atypical presentation of Clostridium difficile colitis in patients with cystic fibrosis. Am. J. Roentgenol. 172 (2), 517-521.

Blaser, M., 2011. Antibiotic overuse: stop the killing of beneficial bacteria. Nature 476 (7361), 393-394.

Brismar, B., et al., 1991. Comparative effects of clarithromycin and erythromycin on the normal intestinal microflora. Scand. J. Infect. Dis. 23 (5), 635-642.

Brüssow, H., 2012. Pseudomonas biofilms, cystic fibrosis, and phage: a silver lining? MBio 3 (2), e00061-12.

Bruzzese, E., et al., 2004. Intestinal inflammation is a frequent feature of cystic fibrosis and is reduced by probiotic administration. Aliment. Pharmacol. Ther. 20 (7), 813-819.

Bruzzese, E., et al., 2007. Effect of Lactobacillus GG supplementation on pulmonary exacerbations in patients with cystic fibrosis: a pilot study. Clin. Nutr. 26 (3), 322-328.

Bruzzese, E., et al., 2014. Disrupted intestinal microbiota and intestinal inflammation in children with cystic fibrosis and its restoration with Lactobacillus GG: a randomised clinical trial. PLoS One 9 (2), e87796.

Bryan, L.E., Kowand, S.K., Van Den Elzen, H.M., 1979. Mechanism of aminoglycoside antibiotic resistance in anaerobic bacteria: Clostridium perfringens and Bacteroides fragilis. Antimicrob. Agents Chemother 15 (1), 7-13.

Bush, K., Jacoby, G.A., 2010. Updated functional classification of $\beta$-lactamases. Antimicrob. Agents Chemother. 54 (3), 969-976. 
Cao, Y., Rocha, E.R., Jeffrey Smith, C., 2014. Efficient utilization of complex N-linked glycans is a selective advantage for Bacteroides fragilis in extraintestinal infections. Proc. Nat. Acad. Sci. 111 (35), 12901-12906.

CDC, 2013. Antibiotic Resistance threats in the United States, 2013. Centre for Disease Control. GA, Atlanta. http://www.cdc.gov/drugresistance/threat-report-2013/.

CFRI Annual Report, 2011. http://www.cfri.ie/docs/annual_reports/CFRI2011.pdf.

Chang, J.Y., et al., 2008. Decreased diversity of the fecal microbiome in recurrent Clostridium difficile—associated diarrhea. J. Infect. Dis. 197 (3), 435-438.

Collins, F.S., May 8 , 1992. Cystic fibrosis: molecular biology and therapeutic implications. Science 256 (5058), 774-779.

Claesson, M.J., Jeffery, I.B., Conde, S., Power, S.E., O’Connor, E.M., Cusack, S., et al., 2012. Gut microbiota composition correlates with diet and health in the elderly. Nature 488 (7410), 178-184.

Cornely, O.A., Nathwani, D., Ivanescu, C., Odufowora-Sita, O., Retsa, P., Odeyemi, I.A., 2014. Clinical efficacy of fidaxomicin compared with vancomycin and metronidazole in Clostridium difficile infections: a meta-analysis and indirect treatment comparison. J. Antimicrob. Chemother. dku261.

Cotter, P.D., Stanton, C., Ross, R.P., Hill, C., 2012. The impact of antibiotics on the gut microbiota as revealed by high throughput DNA sequencing. Dis. Med. 13 (70), 193-199.

Cramer, J.P., Burchard, G.D., Lohse, A.W., 2008. Old dogmas and new perspectives in antibioticassociated diarrhea. Medizinische Klinik (Munich, Germany: 1983) 103 (5), 325-338.

Cresti, S., et al., 2002. Resistance determinants and clonal diversity in group A streptococci collected during a period of increasing macrolide resistance. Antimicrob. Agents Chemother. 46 (6), 1816-1822.

Damodaran, S.E., Madhan, S., 2011. Telavancin: a novel lipoglycopeptide antibiotic. J. Pharmacol. Pharmacother. 2 (2), 135.

Davies, J., 1994. Inactivation of antibiotics and the dissemination of resistance genes. Science 264 (5157), 375-382.

Davies, J., Davies, D., 2010. Origins and evolution of antibiotic resistance. Microbiol. Mol. Biol. Rev. 74 (3), 417-433.

Davis, P.B., 2006. Cystic fibrosis since 1938. Am. J. Respir. Crit. Care Med. 173 (5), 475-482.

Debarbieux, L., Leduc, D., Maura, D., Morello, E., Criscuolo, A., Grossi, O., Balloy, V., Touqui, L., 2010. Bacteriophages can treat and prevent Pseudomonas aeruginosa lung infections. J. Infect. Dis. 201 (7), 1096-1104.

De Filippo, C., Cavalieri, D., Di Paola, M., Ramazzotti, M., Poullet, J.B., Massart, S., et al., 2010. Impact of diet in shaping gut microbiota revealed by a comparative study in children from Europe and rural Africa. Proc. Nat. Acad. Sci. 107 (33), 14691-14696.

De La Cochetière, M.-F., et al., 2008. Effect of antibiotic therapy on human fecal microbiota and the relation to the development of Clostridium difficile. Microb. Ecol. 56 (3), 395-402.

Deshpande, L.M., Rhomberg, P.R., Sader, H.S., Jones, R.N., 2006. Emergence of serine carbapenemases (KPC and SME) among clinical strains of Enterobacteriaceae isolated in the United States medical centers: report from the MYSTIC program (1999-2005). Diag. Microbiol. Infect. Dis. 56 (4), 367-372.

Dethlefsen, L., et al., 2008. The pervasive effects of an antibiotic on the human gut microbiota, as revealed by deep 16S rRNA sequencing. PLoS Biol. 6 (11), e280.

Dethlefsen, L., Relman, D.A., 2011. Incomplete recovery and individualised responses of the human distal gut microbiota to repeated antibiotic perturbation. PNAS 108, 4554-4561. 
Dicksved, J., Halfvarson, J., Rosenquist, M., Järnerot, G., Tysk, C., Apajalahti, J., et al., 2008. Molecular analysis of the gut microbiota of identical twins with Crohn's disease. ISME J. 2 (7), 716-727.

Diggs, N.G., Surawicz, C.M., 2009. Evolving concepts in Clostridium difficile colitis. Curr. Gastroenterol. Rep. 11 (5), 400-405.

Diniz, C.G., Santos, S.G., Pestana, A.C.N., Farias, L.M., Carvalho, M.A.R., 2000. Chromosomal breakage in the $B$. fragilis group induced by metronidazole treatment. Anaerobe 6 (3), 149-153.

Dodge, J.A., Turck, D., 2006. Cystic fibrosis: nutritional consequences and management. Best Prac. Res. Clin. Gastroenterol. 20 (3), 531-546.

Döring, G., Conway, S.P., Heijerman, H.G.M., Hodson, M.E., Høiby, N., Smyth, A., et al., 2000. Antibiotic therapy against Pseudomonas aeruginosa in cystic fibrosis: a European consensus. Eur. Respir. J. 16 (4), 749-767.

Döring, G., Flume, P., Heijerman, H., Elborn, J.S., Consensus Study Group, 2012. Treatment of lung infection in patients with cystic fibrosis: current and future strategies. J. Cystic Fibrosis 11 (6), 461-479.

Dortet, L., Poirel, L., Nordmann, P., 2012. Rapid detection of carbapenemase-producing Pseudomonas species. J. Clin. Microbiol. 01597.

Drlica, K., 1999. Mechanism of fluoroquinolone action. Curr. Opin. Microbiol. 2 (5), 504-508.

Duytschaever, G., Huys, G., Bekaert, M., Boulanger, L., De Boeck, K., Vandamme, P., 2011. Cross-sectional and longitudinal comparisons of the predominant fecal microbiota compositions of a group of pediatric patients with cystic fibrosis and their healthy siblings. Appl. Environ. Microbiol. 77 (22), 8015-8024.

Duytschaever, G., Huys, G., Bekaert, M., Boulanger, L., De Boeck, K., Vandamme, P., 2013. Dysbiosis of bifidobacteria and Clostridium cluster XIVa in the cystic fibrosis fecal microbiota. J. Cystic Fibrosis 12 (3), 206-215.

ECDC, 2015. European Surveillance of Clostridium Difficile Infections. Surveillance Protocol Version 2.1. European Centre for Disease Prevention and Control, Stockholm.

Edlund, C., Beyer, G., Lode, H., et al., 2000. Comparative effects of moxifloxacin and clarithromycin on the normal intestinal microflora. Scand. J. Infect. Dis. 32, 81-85.

Eichenwald, H.F., McCracken, G.H., 1978. Antimicrobial therapy in infants and children: Part I. Review of antimicrobial agents. J. Pediatr 93 (3), 337-356.

Elphick, H.E., Tan, A.A., 2005. Single versus combination intravenous antibiotic therapy for people with cystic fibrosis. Cochrane Library CD002007.

Engelbrektson, A.L., et al., 2006. Analysis of treatment effects on the microbial ecology of the human intestine. FEMS Microbiol. Ecol. 57 (2), 239-250.

Faria, A.M., Weiner, H.L., 2005. Oral tolerance. Immunol. Rev. 206, 232-259.

Farrell, P.M., 2008. The prevalence of cystic fibrosis in the European Union. J. Cyst. Fibros 7 (5), 450-453.

Fieker, A., Philpott, J., Armand, M., 2011. Enzyme replacement therapy for pancreatic insufficiency: present and future. Clin. Exp. Gastroenterol. 4, 55.

Flume, P.A., Mogayzel Jr., P.J., Robinson, K.A., Goss, C.H., Rosenblatt, R.L., Kuhn, R.J., Marshall, B.C., 2009. Cystic fibrosis pulmonary guidelines: treatment of pulmonary exacerbations. Am. J. Respir. Crit. Care Med. 180 (9), 802-808.

Fouhy, F., Ogilvie, L.A., Jones, B.V., Ross, R.P., Ryan, A.C., et al., 2014. Identification of aminoglycoside and $\beta$-lactam resistance genes from within an infant gut functional metagenomic library. PLoS One 9 (9), e108016. 
Foulstone, M., Reading, C., 1982. Assay of amoxicillin and clavulanic acid, the components of Augmentin, in biological fluids with high-performance liquid chromatography. Antimicrob. Agents Chemother. 22 (5), 753-762.

Gerding, D.N., 2004. Clindamycin, cephalosporins, fluoroquinolones, and Clostridium difficile-associated diarrhea: this is an antimicrobial resistance problem. Clin. Infect. Dis. 38 (5), 646-648.

Gibson, R.L., Burns, J.L., Ramsey, B.W., 2003. Pathophysiology and management of pulmonary infections in cystic fibrosis. Am. J. Respir. Crit. Care Med. 168 (8), 918-951.

Gould, I.M., van der Meer, J.W. (Eds.), 2007. Antibiotic Policies: Fighting Resistance. Springer.

Guarner, F., et al., 2006. Mechanisms of disease: the hygiene hypothesis revisited. Nat. Clin. Pract. Gastroenterol. Hepatol. 3 (5), 275-284.

Guarner, F., 2007. Hygiene, microbial diversity and immune regulation. Curr. Opin. Gastroenterol. 23 (6), 667-672.

Gupta, A., et al., 2003. A new Bacteroides conjugative transposon that carries an ermB gene. Appl. Environ. Microbiol. 69 (11), 6455-6463.

Gutacker, M., et al., 2000. Identification of two genetic groups in Bacteroides fragilis by multilocus enzyme electrophoresis: distribution of antibiotic resistance (cfiA, cepA) and enterotoxin (bft) encoding genes. Microbiology 146 (5), 1241-1254.

Gutiérrez, O., Juan, C., Cercenado, E., Navarro, F., Bouza, E., Coll, P., et al., 2007. Molecular epidemiology and mechanisms of carbapenem resistance in Pseudomonas aeruginosa isolates from Spanish hospitals. Antimicrob. Agents Chemother. 51 (12), 4329-4335.

Hamilton-Miller, J.M.T., 1992. In-vitro activities of 14-, 15- and 16-membered macrolides against gram-positive cocci. J. Antimicrob. Chemother. 29 (2), 141-147.

Hammad, A.M., Shimamoto, T., 2010. Towards a compatible probiotic-antibiotic combination therapy: assessment of antimicrobial resistance in the Japanese probiotics. J. Appl. Microbiol. 109 (4), 1349-1360.

Harrison, M.J., McCarthy, M., Fleming, C., Hickey, C., Shortt, C., Eustace, J.A., Murphy, D.M., Plant, B.J., 2014. Inhaled versus nebulised tobramycin: a real world comparison in adult cystic fibrosis (CF). J. Cystic Fibrosis 13 (6), 692-698.

Hedberg, M., Nord, C.E., 2002. Anaerobic Bacteria. Antimicrobial Therapy and Vaccines, second ed. Apple Tree Productions, New York, pp. 55-62.

Hempel, S., Newberry, S.J., Maher, A.R., Wang, Z., Miles, J.N., Shanman, R., et al., 2012. Probiotics for the prevention and treatment of antibiotic-associated diarrhea: a systematic review and meta-analysis. JAMA 307 (18), 1959-1969.

Herrmann, G., Yang, L., Wu, H., Song, Z., Wang, H., et al., 2010. Colistin-tobramycin combinations are superior to monotherapy concerning the killing of biofilm Pseudomonas aeruginosa. J. Infect. Dis. 202, 1585-1592. http://dx.doi.org/10.1086/656788. PubMed: 20942647.

Hertz, F.B., Løbner-Olesen, A., Frimodt-Møller, N., 2014. Antibiotic selection of Escherichia coli sequence type 131 in a mouse intestinal colonization model. Antimicrob. Agents Chemother. 58 (10), 6139-6144.

Hildebrandt, M.A., Hoffmann, C., Sherrill-Mix, S.A., Keilbaugh, S.A., Hamady, M., Chen, Y.Y., et al., 2009. High-fat diet determines the composition of the murine gut microbiome independently of obesity. Gastroenterology 137 (5), 1716-1724.

Høiby, N., 1993. Antibiotic therapy for chronic infection of Pseudomonas in the lung. Ann. Review Med. 44, 1-10. 
Holten, K.B., Onusko, E.M., 2000. Appropriate prescribing of oral beta-lactam antibiotics. Am. Fam. Physician 62 (3), 611-620.

Hooper, D.C., 2001. Emerging mechanisms of fluoroquinolone resistance. Emerging Infect. Dis. 7 (2), 337.

Hewer, S.C.L., Smyth, A.R., 2014. Antibiotic strategies foreradicating Pseudomonas aeruginosa in people with cystic fibrosis. Cochrane Library. http://dx.doi.org/10.1002/14651858.

Iapichino, G., Callegari, M.L., Marzorati, S., Cigada, M., Corbella, D., Ferrari, S., Morelli, L., 2008. Impact of antibiotics on the gut microbiota of critically ill patients. J. Med. Microbiol. 57 (8), 1007-1014.

Isaacs, K., Herfarth, H., 2008. Role of probiotic therapy in IBD. Inflammation Bowel Dis. 14 (11), 1597-1605.

Jakobsson, H.E., et al., 2010. Short-term antibiotic treatment has differing long-term impacts on the human throat and gut microbiome. PLoS One 5 (3), e9836.

Jeong, S.H., et al., 2009. Risk assessment of ciprofloxacin, flavomycin, olaquindox and colistin sulfate based on microbiological impact on human gut biota. Regul. Toxicol. Pharmacol. 53 (3), 209-216.

Jernberg, C., et al., 2007. Long-term ecological impacts of antibiotic administration on the human intestinal microbiota. ISME J. 1 (1), 56-66.

Jernberg, C., et al., 2010. Long-term impacts of antibiotic exposure on the human intestinal microbiota. Microbiology 156 (Pt 11), 3216-3223.

Jousimies-Somer, H.R., Summanen, P., Citron, D.M., Baron, E.J., Wexler, H.M., Finegold, S.M., 2002. Anaerobic Bacteriology Manual. Star Publishing Company, BelmontCalifornia.

Kawamura-Sato, K., et al., 2000. Effect of subinhibitory concentrations of macrolides on expression of flagellin in Pseudomonas aeruginosa and Proteus mirabilis. Antimicrob. Agents Chemother. 44 (10), 2869-2872.

Knecht, H., et al., 2014. Effects of $\beta$-lactam antibiotics and fluoroquinolones on human gut microbiota in relation to Clostridium difficile associated diarrhea. PLoS One 9 (2), e89417.

Koch, C., Rainisio, M., Madessani, U., Harms, H.K., Hodson, M.E., Mastella, G., et al., 2001. Presence of cystic fibrosis-related diabetes mellitus is tightly linked to poor lung function in patients with cystic fibrosis: data from the European epidemiologic registry of cystic fibrosis. Pediatr. Pulmonol. 32 (5), 343-350.

Koenigsknecht, M.J., Young, V.B., 2013. Faecal microbiota transplantation for the treatment of recurrent Clostridium difficile infection: current promise and future needs. Curr. Opin. Gastroenterol. 29 (6), 628-632.

Konstan, M.W., Flume, P.A., Kappler, M., Chiron, R., Higgins, M., Brockhaus, F., et al., 2011. Safety, efficacy and convenience of tobramycin inhalation powder in cystic fibrosis patients: the EAGER trial. J. Cystic Fibrosis 10 (1), 54-61.

Kouda, S., Ohara, M., Onodera, M., Fujiue, Y., Sasaki, M., Kohara, T., et al., 2009. Increased prevalence and clonal dissemination of multidrug-resistant Pseudomonas aeruginosa with the blaIMP-1 gene cassette in Hiroshima. J. Antimicrob. Chemother. dkp142.

Kuijper, E.J., Barbut, F., Brazier, J.S., Kleinkauf, N., Eckmanns, T., Lambert, M.L., et al., 2008. Update of Clostridium difficile Infection due to PCR Ribotype 027 in Europe.

Kyne, L., Warny, M., Qamar, A., Kelly, C.P., 2000. Asymptomatic carriage of Clostridium difficile and serum levels of IgG antibody against toxin A. N. Engl. J. Med. 342, 390-397.

Lagatolla, C., Edalucci, E., Dolzani, L., Riccio, M.L., De Luca, F., Medessi, E., et al., 2006. Molecular evolution of metallo- $\beta$-lactamase-producing Pseudomonas aeruginosa in a nosocomial setting of high-level endemicity. J. Clin. Microbiol. 44 (7), 2348-2353.

Lamp, K.C., Freeman, C.D., Klutman, N.E., Lacy, M.K., 1999. Pharmacokinetics and pharmacodynamics of the nitroimidazole antimicrobials. Clin. Pharmacokinet. 36 (5), 353-373. 
Land, K.M., Johnson, P.J., 1999. Molecular basis of metronidazole resistance in pathogenic bacteria and protozoa. Drug Resist. Updates 2 (5), 289-294.

Larsen, N., Vogensen, F.K., Van Den Berg, F.W., Nielsen, D.S., Andreasen, A.S., Pedersen, B.K., et al., 2010. Gut microbiota in human adults with type 2 diabetes differs from nondiabetic adults. PloS One 5 (2), e9085.

Laxminarayan, R., Heymann, D.L., 2012. Challenges of drug resistance in the developing world. BMJ 344, e1567.

Laxminarayan, R., Duse, A., Wattal, C., Zaidi, A.K., Wertheim, H.F., Sumpradit, N., et al., 2013. Antibiotic resistance - the need for global solutions. Lancet Infect. Dis. 13 (12), 1057-1098.

Lee, J.H., O’Sullivan, D.J., 2010. Genomic insights into bifidobacteria. Microbiol. Mol. Biol. Rev. 74 (3), 378-416.

Leiros, H.K.S., Kozielski-Stuhrmann, S., Kapp, U., Terradot, L., Leonard, G.A., McSweeney, S.M., 2004. Structural basis of 5-Nitroimidazole antibiotic resistance. The crystal structure of nimA from Deinococcus radiodurans. J. Biol. Chem. 279 (53), 55840-55849.

Leung, C.H., Lam, W., Ma, D.L., Gullen, E.A., Cheng, Y.C., 2009. Butyrate mediates nucleotide-binding and oligomerisation domain (NOD) 2-dependent mucosal immune responses against peptidoglycan. Eur. J. Immunol. 39 (12), 3529-3537.

Lewis, K., 2013. Platforms for antibiotic discovery. Nat. Rev. Drug Dis. 12 (5), 371-387.

Lidbeck, A., et al., 1988. Impact of Lactobacillus acidophilus on the normal intestinal microflora after administration of two antimicrobial agents. Infection 16 (6), 329-336.

Littlewood, J.M., MacDonald, A., 1987. Rationale of modern dietary recommendations in cystic fibrosis. J. Royal Soc. Med. 80 (Suppl. 15), 16.

Littlewood, J., et al., 2000. A ten year review of colomycin. Respir. Med. 94 (7), 632-640.

Liu, P., Müller, M., Derendorf, H., 2002. Rational dosing of antibiotics: the use of plasma concentrations versus tissue concentrations. Int. J. Antimicrob. Agents 19 (4), 285-290.

Liu, P., Derendorf, H., 2003. Antimicrobial tissue concentrations. Infect. Dis. Clin. North Am. 17 (3), 599-613.

Löfmark, S., Edlund, C., Nord, C.E., 2010. Metronidazole is still the drug of choice for treatment of anaerobic infections. Clin. Infect. Dis. 50 (Suppl. 1), S16-S23.

Lozupone, C.A., Stombaugh, J.I., Gordon, J.I., Jansson, J.K., Knight, R., 2012. Diversity, stability and resilience of the human gut microbiota. Nature 489 (7415), 220-230.

Lu, N., Hu, Y., Zhu, L., Yang, X., Yin, Y., Lei, F., et al., 2014. DNA Microarray Analysis Reveals that Antibiotic Resistance-gene Diversity in Human Gut Microbiota Is Age Related. Scientific Reports, p. 4.

Madan, J.C., Koestler, D.C., Stanton, B.A., Davidson, L., Moulton, L.A., Housman, M.L., et al., 2012. Serial analysis of the gut and respiratory microbiome in cystic fibrosis in infancy: interaction between intestinal and respiratory tracts and impact of nutritional exposures. mBio 3 (4), e00251-12.

Manges, A.R., Labbe, A., Loo, V.G., et al., 2010. Comparative metagenomic study of alterations to the intestinal microbiota and risk of nosocomial Clostridium difficile-associated disease. J. Infect. Dis. 202, 1877-1884.

Marshall, B.C., Butler, S.M., Stoddard, M., Moran, A.M., Liou, T.G., Morgan, W.J., 2005. Epidemiology of cystic fibrosis-related diabetes. J. Pediatr. 146 (5), 681-687.

Marra, F., Lynd, L., Coombes, M., Richardson, K., Legal, M., et al., 2006. Does antibiotic exposure during infancy lead to development of asthma?: A systematic review and metaanalysis. Chest 129, 610-618.

Meyer-Hoffert, U., Hornef, M.W., Henriques-Normark, B., Axelsson, L.G., Midtvedt, T., Pütsep, K., Andersson, M., 2008. Secreted enteric antimicrobial activity localises to the mucus surface layer. Gut 57 (6), 764-771. 
Millard, A., Mertes, P.M., Ittelet, D., Villard, F., Jeannesson, P., Bernard, J., 2002. Butyrate affects differentiation, maturation and function of human monocyte-derived dendritic cells and macrophages. Clin. Exp. Immunol. 130 (2), 245-255.

Miriagou, V., Cornaglia, G., Edelstein, M., Galani, I., Giske, C.G., Gniadkowski, M., et al., 2010. Acquired carbapenemases in Gram-negative bacterial pathogens: detection and surveillance issues. Clin. Microbiol. Infect. 16 (2), 112-122.

Monreal, M.T.F.D., Pereira, P.C.M., Lopes, C.A.D.M., 2005. Intestinal microbiota of patients with bacterial infection of the respiratory tract treated with amoxicillin. Braz. J. Infect. Dis. 9 (4), 292-300.

Morello, E., Saussereau, E., Maura, D., Huerre, M., Touqui, L., Debarbieux, L., 2011. Pulmonary bacteriophage therapy on Pseudomonas aeruginosa cystic fibrosis strains: first steps towards treatment and prevention. PloS One 6 (2), e16963.

Morotomi, N., et al., 2011. Evaluation of intestinal microbiotas of healthy Japanese adults and effect of antibiotics using the $16 \mathrm{~S}$ ribosomal RNA gene based clone library method. Biol. Pharm. Bull. 34 (7), 1011-1020.

Morrissey, I., Hackel, M., Badal, R., Bouchillon, S., Hawser, S., Biedenbach, D., 2013. A review of ten years of the study for monitoring antimicrobial resistance trends (SMART) from 2002 to 2011. Pharmaceuticals 6 (11), 1335-1346.

Moskowitz, S.M., et al., 2008. Shifting patterns of inhaled antibiotic use in cystic fibrosis. Pediatr. Pulmonol. 43 (9), 874-881.

Murphy, E.F., Cotter, P.D., Hogan, A., O’Sullivan, O., Joyce, A., Fouhy, F., et al., 2013. Divergent metabolic outcomes arising from targeted manipulation of the gut microbiota in diet-induced obesity. Gut 62 (2), 220-226.

Na, X., Kelly, C., 2011. Probiotics in Clostridium difficile infection. J. Clin. Gastroenterol. 45, S154-S158.

Nagy, E., Földes, J., 1991. Inactivation of metronidazole by Enterococcus faecalis. J. Antimicrob. Chemother. 27 (1), 63-70.

Nakamura, S., et al., 1981. Isolation of Clostridium difficile from the feces and the antibody in sera of young and elderly adults. Microbiol. Immunol. 25 (4), 345-351.

Nakano, V., et al., 2011. Antimicrobial resistance and prevalence of resistance genes in intestinal Bacteroidales strains. Clinics 66 (4), 543-547.

Navon-Venezia, S., Chmelnitsky, I., Leavitt, A., Schwaber, M.J., Schwartz, D., Carmeli, Y., 2006. Plasmid-mediated imipenem-hydrolyzing enzyme KPC-2 among multiple carbapenem-resistant Escherichia coli clones in Israel. Antimicrob. Agents Chemother. 50 (9), 3098-3101.

Noverr, M.C., Huffnagle, G.B., 2005. The 'microflora hypothesis' of allergic diseases. Clin. Exp. Allergy 35, 1511-1520.

Ochman, H., et al., 2000. Lateral gene transfer and the nature of bacterial innovation. Nature 405 (6784), 299-304.

O'Loughlin, C.T., Miller, L.C., Siryaporn, A., Drescher, K., Semmelhack, M.F., Bassler, B.L., 2013. A quorum-sensing inhibitor blocks Pseudomonas aeruginosa virulence and biofilm formation. Proc. Nat. Acad. Sci. 110 (44), 17981-17986.

O'Sullivan, Ó., Coakley, M., Lakshminarayanan, B., Conde, S., Claesson, M.J., Cusack, S., et al., 2012. Alterations in intestinal microbiota of elderly Irish subjects post-antibiotic therapy. J. Antimicrob. Chemother. http://dx.doi.org/10.1093/jac/dks348.

O'Sullivan, O., et al., 2013. Alterations in intestinal microbiota of elderly Irish subjects postantibiotic therapy. J. Antimicrob. Chemother. 68 (1), 214-221. 
Ouwehand, A.C., Salminen, S., Isolauri, E., 2002. Probiotics: an overview of beneficial effects. Antonie Van Leeuwenhoek 82 (1-4), 279-289.

Owens, R.C., et al., 2008. Antimicrobial-associated risk factors for Clostridium difficile infection. Clin. Infect. Dis. 46 (Suppl. 1), S19-S31.

Ozaki, E., et al., 2004. Clostridium difficile colonization in healthy adults: transient colonization and correlation with enterococcal colonization. J. Med. Microbiol. 53 (2), 167-172.

Page, M.G., 2012. Beta-lactam Antibiotics. Antibiotic Discovery and Development. Springer, pp. 79-117.

Pamp, S.J., Gjermansen, M., Johansen, H.K., Tolker-Nielsen, T., 2008. Tolerance to the antimicrobial peptide colistin in Pseudomonas aeruginosa biofilms is linked to metabolically active cells, and depends on the pmr and mexAB-oprM genes. Mol. Microbiol. 68, 223-240. http://dx.doi.org/10.1111/j.1365-2958.2008.06152.x. PubMed:18312276.

Pamukcu, A., Bush, A., Buchdahl, R., 1995. Effects of Pseudomonas aeruginosa colonization on lung function and anthropometric variables in children with cystic fibrosis. Pediatr. Pulmonol. 19, 10-15.

Peach, S.L., Borriello, S.P., Gaya, H., Barclay, F.E., Welch, A.R., September 1986. Asymptomatic carriage of Clostridium difficile in patients with cystic fibrosis. J. Clin. Pathol. 39 (9), 1013-1018.

Pencharz, P.B., Durie, P.R., 1993. Nutritional management of cystic fibrosis. Ann. Rev. Nutr. 13 (1), 111-136.

Pepin, J., Valiquette, L., Cossette, B., 2005. Mortality attributable to nosocomial Clostridium difficile-associated disease during an epidemic caused by a hypervirulent strain in Quebec. CMAJ 173, 1-6.

Perez-Cobas, A.E., et al., 2013. Differential effects of antibiotic therapy on the structure and function of human gut microbiota. PLoS One 8 (11), e80201.

Petrof, E.O., Gloor, G.B., Vanner, S.J., Weese, S.J., Carter, D., Daigneault, M.C., et al., 2013. Stool substitute transplant therapy for the eradication of Clostridium difficile infection: 'RePOOPulating' the gut. Microbiome 1 (1), 1-12.

Perron, G.G., Kryazhimskiy, S., Rice, D.P., Buckling, A., 2012. Multidrug therapy and evolution of antibiotic resistance: when order matters. Appl. Environ. Microbiol. 78 (17), 6137-6142.

Pitout, J.D., Chow, B.L., Gregson, D.B., Laupland, K.B., Elsayed, S., Church, D.L., 2007. Molecular epidemiology of metallo- $\beta$-lactamase-producing Pseudomonas aeruginosa in the Calgary Health Region: emergence of VIM-2-producing isolates. J. Clin. Microbiol. 45 (2), 294-298.

Pitout, J.D., Laupland, K.B., 2008. Extended-spectrum $\beta$-lactamase-producing Enterobacteriaceae: an emerging public-health concern. Lancet Infect. Dis. 8 (3), 159-166.

Plant, B.J., Goss, C.H., Plant, W.D., Bell, S.C., 2013. Management of comorbidities in older patients with cystic fibrosis. Lancet Respir. Med. 1 (2), 164-174.

Power, S.E., O’Toole, P.W., Stanton, C., Ross, R.P., Fitzgerald, G.F., 2014. Intestinal microbiota, diet and health. Br. J. Nutr. 111 (03), 387-402.

Pumbwe, L., et al., 2007. Bile salts enhance bacterial co-aggregation, bacterial-intestinal epithelial cell adhesion, biofilm formation and antimicrobial resistance of Bacteroides fragilis. Microb. Pathog. 43 (2), 78-87.

Queenan, A.M., Bush, K., 2007. Carbapenemases: the versatile $\beta$-lactamases. Clin. Microbiol. Rev. 20 (3), 440-458.

Quinton, P.M., 1990. Righting the wrong protein. Nature 347 (6290), 226. 
Ramsey, B.W., Pepe, M.S., Quan, J.M., Otto, K.L., Montgomery, A.B., Williams-Warren, J., et al., 1999. Intermittent administration of inhaled tobramycin in patients with cystic fibrosis. New England J. Med. 340 (1), 23-30.

Ratjen, F., Döring, G., Nikolaizik, W.H., 2001. Effect of inhaled tobramycin on early Pseudomonas aeruginosa colonisation in patients with cystic fibrosis. Lancet 358 (9286), 983-984.

Rea, M.C., Sit, C.S., Clayton, E., O'Connor, P.M., Whittal, R.M., Zheng, J., et al., 2010. Thuricin CD, a posttranslationally modified bacteriocin with a narrow spectrum of activity against Clostridium difficile. Proc. Nat. Acad. Sci. 107 (20), 9352-9357.

Rea, M.C., Dobson, A., O'Sullivan, O., Crispie, F., Fouhy, F., Cotter, P.D., et al., 2011. Effect of broad-and narrow-spectrum antimicrobials on Clostridium difficile and microbial diversity in a model of the distal colon. Proc. Nat. Acad. Sci. 108 (Suppl. 1), 4639-4644.

Reynolds, P.E., November 1989. Structure, biochemistry and mechanism of action of glycopeptide antibiotics. Eur. J. Clin. Microbiol. Infect. Dis. 8 (11), 943-950. Endocarditis due to resistant organisms.

Reysset, G., 1996. Genetics of 5-Nitroimidazole resistance in Bacteroides species. Anaerobe 2 (2), 59-69.

Report EEJT, 2009. The bacterial challenge: time to react. A call to narrow the gap between multidrug-resistant bacteria in the EU and the development of new antibacterial agents. http:// wwwemeaeuropaeu/docs/en_GB/document_library/Report/2009/11/WC500008770pdf.

Roca, I., Akova, M., Baquero, F., Carlet, J., Cavaleri, M., Coenen, S., Cohen, J., et al., 2015. The global threat of antimicrobial resistance: science for intervention. New Microbes New Infect. http://dx.doi.org/10.1016/j.nmni.2015.02.007.

Rolain, J.M., Parola, P., Cornaglia, G., 2010. New Delhi metallo-beta-lactamase (NDM-1): towards a new pandemia? Clin. Microbiol. Infect. 16 (12), 1699-1701.

Rodier, D.G., 2011. European Strategic Action Plan on Antibiotic Resistance. http:// wwweurowhoint/__data/assets/pdf_file/0011/148988/RC61_Pres_Rodier_ antibiotic_resistancepdf.

Rolfe, R.D., Helebian, S., Finegold, S.M., March 1981. Bacterial interference between Clostridium difficile and normal fecal flora. J. Infect. Dis. 143, 470-475.

Rousseau, C., et al., 2011. Clostridium difficile colonization in early infancy is accompanied by changes in intestinal microbiota composition. J. Clin. Microbiol. 49 (3), 858-865.

Russell, D.A., Ross, R.P., Fitzgerald, G.F., Stanton, C., 2011. Metabolic activities and probiotic potential of bifidobacteria. Int. J. Food Microbiol. 149 (1), 88-105.

Saiman, L., Marshall, B.C., Mayer-Hamblett, N., Burns, J.L., Quittner, A.L., Cibene, D.A., et al., 2003. Azithromycin in patients with cystic fibrosis chronically infected with Pseudomonas aeruginosa: a randomized controlled trial. JAMA 290 (13), 1749-1756.

Salyers, A.A., 1984. Bacteroides of the human lower intestinal tract. Ann. Rev. Microbiol. 38 (1), 293-313.

Salyers, A.A., et al., 2004. Human intestinal bacteria as reservoirs for antibiotic resistance genes. Trends Microbiol. 12 (9), 412-416.

Sawicki, G.S., Tiddens, H., 2012. Managing treatment complexity in cystic fibrosis: challenges and opportunities. Pediatr. Pulmonol. 47 (6), 523-533.

Scanlan, P.D., Buckling, A., Kong, W., Wild, Y., Lynch, S.V., Harrison, F., 2012. Gut dysbiosis in cystic fibrosis. J. Cystic Fibrosis 11 (5), 454-455.

Schippa, S., Iebba, V., Santangelo, F., Gagliardi, A., De Biase, R.V., Stamato, A., et al., 2013. Cystic fibrosis transmembrane conductance regulator (CFTR) allelic variants relate to shifts in faecal microbiota of cystic fibrosis patients. PloS One 8 (4), e61176. 
Schloissnig, S., Arumugam, M., Sunagawa, S., Mitreva, M., Tap, J., Zhu, A., et al., 2013. Genomic variation landscape of the human gut microbiome. Nature 493 (7430), 45-50.

Schuster, A., Cynthia, H., Gerd, D., Martin, H.G., Freedom Study Group, 2013. Safety, efficacy and convenience of colistimethate sodium dry powder for inhalation (Colobreathe DPI) in patients with cystic fibrosis: a randomised study. Thorax 68 (4), 344-350.

Scott, K.P., Duncan, S.H., Flint, H.J., 2008. Dietary fibre and the gut microbiota. Nutr. Bull. 33 (3), 201-211.

Sharma, D., Singh Saharan, B., 2014. Simultaneous production of biosurfactants and bacteriocins by probiotic Lactobacillus casei MRTL3. Int. J. Microbiol. 2014.

Shipman, J.A., Berleman, J.E., Salyers, A.A., 2000. Characterization of four outer membrane proteins involved in binding starch to the cell surface of Bacteroides thetaiotaomicron. J. Bacteriol. 182 (19), 5365-5372.

Shoemaker, N.B., et al., 2001. Evidence for extensive resistance gene transfer among Bacteroides species and among Bacteroides and other genera in the human colon. Appl. Environ. Microbiol. 67 (2), 561-568.

Sjölund, M., et al., 2003. Long-term persistence of resistant Enterococcus species after antibiotics to eradicate Helicobacter pylori. Ann. Intern. Med. 139 (6), 483-487.

Smyth, A.R., Bell, S.C., Bojcin, S., Bryon, M., Duff, A., Flume, P., et al., 2014. European cystic fibrosis society standards of care: best practice guidelines. J. Cystic Fibrosis 13, S23-S42.

Somaraju, U.R., Solis-Moya, A., 2014. Pancreatic enzyme replacement therapy for people with cystic fibrosis. Cochrane Library. http://dx.doi.org/10.1002/14651858.

Sommer, M.O., et al., 2009. Functional characterization of the antibiotic resistance reservoir in the human microflora. Science 325 (5944), 1128-1131.

Stark, C., et al., 1993. Antimicrobial resistance in human oral and intestinal anaerobic microfloras. Antimicrob. Agents Chemother. 37 (8), 1665-1669.

Stecenko, A.A., Moran, A., 2010. Update on cystic fibrosis-related diabetes. Curr. Opin. Pulm. Med. 16 (6), 611-615.

Storm, D.R., et al., 1977. Polymyxin and related peptide antibiotics. Ann. Rev. Biochem. 46 (1), 723-763.

Strominger, J.L., Tipper, D.J., 1965. Bacterial cell wall synthesis and structure in relation to the mechanism of action of penicillins and other antibacterial agents. Am. J. Med. 39 (5), 708-721.

Sullivan, A., Edlund, C., Nord, C.E., 2001. Effect of antimicrobial agents on the ecological balance of human microflora. Lancet Infect. Dis. 1, 101-114.

Surawicz, C.M., Brandt, L.J., Binion, D.G., Ananthakrishnan, A.N., Curry, S.R., Gilligan, P.H., et al., 2013. Guidelines for diagnosis, treatment, and prevention of Clostridium difficile infections. Am. J. Gastroenterol. 108 (4), 478-498.

Szaff, M., Høiby, N., Flensborg, E.W., 1983. Frequent antibiotic therapy improves survival of cystic fibrosis patients with chronic Pseudomonas aeruginosa infection. Acta Paediatr. 72 (5), 651-657.

Taccetti, G., Campana, S., Festini, F., Mascherini, M., Döring, G., 2005. Early eradication therapy against Pseudomonas aeruginosa in cystic fibrosis patients. Eur. Respir. J. 26 (3), 458-461.

Taylor, S., et al., 1993. Glutathione peroxidase protects cultured mammalian cells from the toxicity of adriamycin and paraquat. Arch. Biochem. Biophys. 305 (2), 600-605.

Tipper, D., 1979. Mode of action of $\beta$-lactam antibiotics. Rev. Infect. Dis. 1 (1), 39-53.

Tenson, T., Lovmar, M., Ehrenberg, M., 2003. The mechanism of action of macrolides, lincosamides and streptogramin B reveals the nascent peptide exit path in the ribosome. J. Mol. Biol. 330 (5), 1005-1014. 
Terhes, G., Maruyama, A., Latkóczy, K., Szikra, L., Konkoly-Thege, M., Princz, G., et al., 2014. In vitro antibiotic susceptibility profile of Clostridium difficile excluding PCR ribotype 027 outbreak strain in Hungary. Anaerobe 41-44.

Turnbaugh, P.J., Ley, R.E., Mahowald, M.A., Magrini, V., Mardis, E.R., Gordon, J.I., 2006. An obesity-associated gut microbiome with increased capacity for energy harvest. Nature 444 (7122), 1027-1131.

Turnbaugh, P.J., Ridaura, V.K., Faith, J.J., Rey, F.E., Knight, R., Gordon, J.I., 2009. The effect of diet on the human gut microbiome: a metagenomic analysis in humanized gnotobiotic mice. Sci. Transl. Med. 1 (6), 6ra14.

Turnbaugh, P.J., Gordon, J.I., 2009. The core gut microbiome, energy balance and obesity. J. Physiol. 587 (17), 4153-4158.

Tvede, M., Rask-Madsen, J., 1989. Bacteriotherapy for chronic relapsing Clostridium difficile diarrhoea in six patients. Lancet 333 (8648), 1156-1160.

Ubeda, C., et al., 2010. Vancomycin-resistant Enterococcus domination of intestinal microbiota is enabled by antibiotic treatment in mice and precedes bloodstream invasion in humans. J. Clin. Invest. 120 (12), 4332-4341.

Udekwu, K.I., Parrish, N., Ankomah, P., Baquero, F., Levin, B.R., 2009. Functional relationship between bacterial cell density and the efficacy of antibiotics. J. Antimicrob. Chemother. http://dx.doi.org/10.1093/jac/dkn554.

Uttley, L., Harnan, S., Cantrell, A., Taylor, C., Walshaw, M., Brownlee, K., Tappenden, P., 2013. Systematic review of the dry powder inhalers colistimethate sodium and tobramycin in cystic fibrosis. Eur. Respir. Rev. 22 (130), 476-486.

Valdez, J.C., Peral, M.C., Rachid, M., Santana, M., Perdigon, G., 2005. Interference of Lactobacillus plantarum with Pseudomonas aeruginosa in vitro and in infected burns: the potential use of probiotics in wound treatment. Clin. Microbiol. Infect. 11, 472-479.

Van Bambeke, F., Van Laethem, Y., Courvalin, P., Tulkens, P.M., 2004. Glycopeptide antibiotics. Drugs 64 (9), 913-936.

Videlock, E.J., Cremonini, F., 2012. Meta-analysis: probiotics in antibiotic-associated diarrhoea. Aliment. Pharmacol. Ther. 35 (12), 1355-1369.

Vighi, G., Marcucci, F., Sensi, L., Di Cara, G., Frati, F., 2008. Allergy and the gastrointestinal system. Clin. Exp. Immunol. 153 (s1), 3-6.

Villegas, M.V., Lolans, K., Correa, A., Kattan, J.N., Lopez, J.A., Quinn, J.P., 2007. First identification of Pseudomonas aeruginosa isolates producing a KPC-type carbapenemhydrolyzing $\beta$-lactamase. Antimicrob. Agents Chemother. 51 (4), 1553-1555.

Viscidi, R., Willey, S., Bartlett, J.G., 1981. Isolation rates and toxigenic potential of Clostridium difficile isolates from various patient populations. Gastroenterology 81, 5-9.

Vonberg, R.P., et al., 2008. Infection control measures to limit the spread of Clostridium difficile. Clin. Microbiol. Infect. 14 (Suppl. 5), 2-20.

Waaij, V., 1989. The ecology of the human intestine and its consequences for overgrowth by pathogens such as Clostridium difficile. Ann. Rev. Microbiol. 43 (1), 69-87.

Wall, M.A., Terry, A.B., Eisenberg, J., McNamara, M., Cohen, R., 1983. Inhaled antibiotics in cystic fibrosis. Lancet 1, 1325.

Walsh, T.R., 2008. Clinically significant carbapenemases: an update. Curr. Opin. Infect. Dis. 21 (4), 367-371.

Warner, J.O., Taylor, B.W., Norman, A.P., Soothill, J.F., 1976. Association of cystic fibrosis with allergy. Arch. Dis. Child. 51 (7), 507-511.

Waters, V., Ratjen, F., 2006. Multidrug-resistant organisms in cystic fibrosis: management and infection-control issues. Expert Rev. Anti Infect. Ther. 4 (5). 
Weiner, H.L., 2000. Oral tolerance, an active immunologic process mediated by multiple mechanisms. J. Clin. Invest. 106, 935-937.

Weiss, B., et al., 2010. Probiotic supplementation affects pulmonary exacerbations in patients with cystic fibrosis: a pilot study. Pediatr. Pulmonol. 45 (6), 536-540.

Welkon, C.J., Long, S.S., Thompson, C.M., Gilligan, P.H., 1985. Clostridium difficile in patients with cystic fibrosis. Am. J. Dis. Child. 139, 805-808.

Wells, J.M., Rossi, O., Meijerink, M., van Baarlen, P., 2011. Epithelial crosstalk at the microbiota-mucosal interface. Proc. Nat. Acad. Sci. 108 (Suppl. 1), 4607-4614.

Werlin, S.L., Benuri-Silbiger, I., Kerem, E., Adler, S.N., Goldin, E., Zimmerman, J., et al., 2010. Evidence of intestinal inflammation in patients with cystic fibrosis. J. Pediatr. Gastroenterol. Nutr. 51 (3), 304-308.

Wexler, H.M., 2007. Bacteroides: the good, the bad, and the nitty-gritty. Clin. Microbiol. Rev. 20 (4), 593-621.

White, H., Morton, A.M., Peckham, D.G., Conway, S.P., 2004. Dietary intakes in adult patients with cystic fibrosis-do they achieve guidelines? J. Cystic Fibrosis 3 (1), 1-7.

WHO, 2006. Toxicological Evaluation of Certain Veterinary Drug Residues in Food, vol. 57. World Health Organization.

Willing, B.P., Russell, S.L., Finlay, B.B., 2011. Shifting the balance: antibiotic effects on hostmicrobiota mutualism. Nat. Rev. Microbiol. 9 (4), 233-243.

Wills-Karp, M., Santeliz, J., Karp, C.L., 2001. The germless theory of allergic disease: revisiting the hygiene hypothesis. Nat. Rev. Immunol. 1 (1), 69-75.

Wolter, J., Seeney, S., Bell, S., Bowler, S., Masel, P., McCormack, J., 2002. Effect of long term treatment with azithromycin on disease parameters in cystic fibrosis: a randomised trial. Thorax 57 (3), 212-216.

Wright, E.A., et al., 2013. Sub-inhibitory concentrations of some antibiotics can drive diversification of Pseudomonas aeruginosa populations in artificial sputum medium. BMC Microbiol. 13, 170.

Wu, G.D., Chen, J., Hoffmann, C., Bittinger, K., Chen, Y.Y., Keilbaugh, S.A., et al., 2011. Linking long-term dietary patterns with gut microbial enterotypes. Science 334 (6052), $105-108$.

Wybo, I., et al., 2007. Third Belgian multicentre survey of antibiotic susceptibility of anaerobic bacteria. J. Antimicrob. Chemother. 59 (1), 132-139.

Xu, J., et al., 2003. A genomic view of the human-Bacteroides thetaiotaomicron symbiosis. Science 299 (5615), 2074-2076.

Xu, D., Gao, J., Gillilland III, M., Wu, X., Song, I., Kao, J.Y., Owyang, C., 2014. Rifaximin alters intestinal bacteria and prevents stress-induced gut inflammation and visceral hyperalgesia in rats. Gastroenterology 146 (2), 484-496.

Yap, M.N., Yang, C.H., Charkowski, A.O., 2008. The response regulator HrpY of Dickeya dadantii 3937 regulates virulence genes not linked to the hrp cluster. Mol. Plant Microbe Inter. 21 (3), 304-314.

Zar, F.A., Bakkanagari, S.R., Moorthi, K.M., Davis, M.B., 2007. A comparison of vancomycin and metronidazole for the treatment of Clostridium difficile-associated diarrhea, stratified by disease severity. Clin. Infect. Dis. 45, 302-307.

Zebouh, M., Thomas, C., Honderlick, P., Lemee, L., Segonds, C., Wallet, F., Husson, M.O., 2008. Direct antimicrobial susceptibility testing method for analysis of sputum collected from patients with cystic fibrosis. J. Cystic Fibrosis 7 (3), 238-243. 